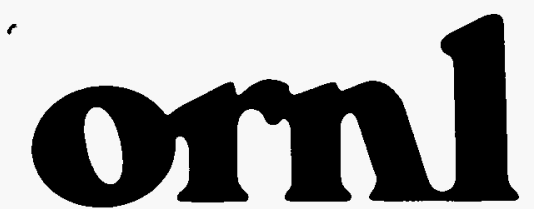

OAK RIDGE NATIONAL LABORATORY

MARTIN MARIETRA
RFCFIVED

MAR 011996

\section{OSTI \\ Thermal-Hydraulic Studies of the Advanced Neutron Source Cold Source}

P. T. Williams

A. T. Lucas

August 1995

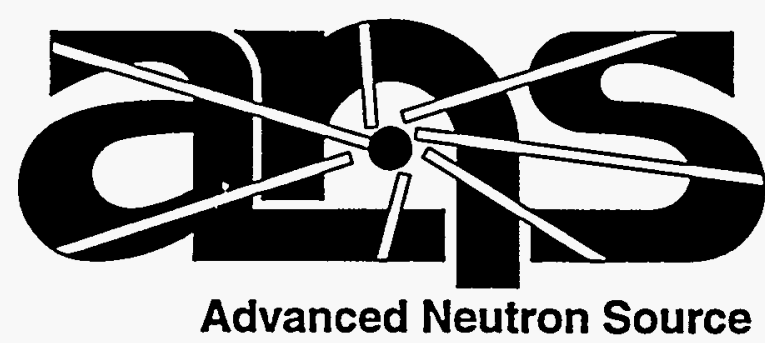

MANAGED BY

MARTIN MARIETTA ENERGY SYSTEMS, INC.

FOR THE UNITED STATES

DEPARTMENT OF ENERGY 
This report has been reproduced directly from the best available copy.

Available to DOE and DOE contractors from the Office of Scientific and Technical Information, P.O. Box 62, Oak Ridge, TN 37831; prices available from (615) 576-8401, FTS 626-8401.

Available to the public from the National Technical Information Service, U.S. Department of Commerce, 5285 Port Royal Rd., Springfield, VA 22161.

This report was prepared as an account of work sponsored by an agency of the United States Government. Neither the United States Government nor any agency thereof, nor any of their employees, makes any warranty, express or implied, or assumes any legal liability or responsibility for the accuracy, completeness, or usefulness of any information, apparatus, product, or process disclosed, or represents that its use would not infringe privately owned rights. Reference herein to any specific commercial product, process, or service by trade name, trademark, manufacturer, or otherwise, does not necessarily constitute or imply its endorsement, recommendation, or favoring by the United States Government or any agency thereof. The views and opinions of authors expressed herein do not necessarily state or reflect those of the United States Government or any agency thereof. 


\title{
THERMAL-HYDRAULIC STUDIES OF THE ADVANCED NEUTRON SOURCE COLD SOURCE
}

\author{
P. T. Williams
}

Computational Physics and Engineering Division

A. T. Lucas

Engineering Technology Division

Date published-August 1995

Prepared by the

OAK RIDGE NATIONAL LABORATORY

Oak Ridge, Tennessee 37831

managed by

LOCKHEED MARTIN ENERGY SYSTEMS, INC.

for the

U.S. DEPARTMENT OF ENERGY

under contract DE-AC05-84OR21400 


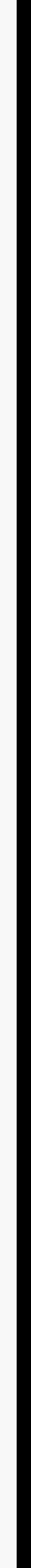


LIST OF FIGURES $\ldots \ldots \ldots \ldots \ldots \ldots \ldots \ldots \ldots \ldots \ldots \ldots \ldots \ldots \ldots \ldots, \mathrm{v}$

LIST OF TABLES $\ldots \ldots \ldots \ldots \ldots \ldots \ldots \ldots \ldots \ldots \ldots \ldots \ldots \ldots \ldots \ldots \ldots \ldots \ldots \ldots$

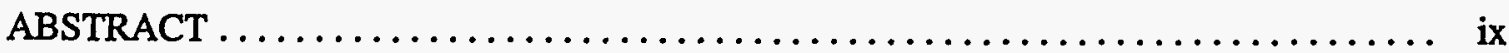

1. INTRODUCTION $\ldots \ldots \ldots \ldots \ldots \ldots \ldots \ldots \ldots \ldots \ldots \ldots \ldots \ldots \ldots \ldots \ldots \ldots \ldots \ldots$

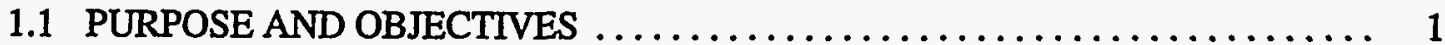

1.2 COLD SOURCE CONCEPTUAL DESIGN $\ldots \ldots \ldots \ldots \ldots \ldots \ldots \ldots \ldots \ldots \ldots$

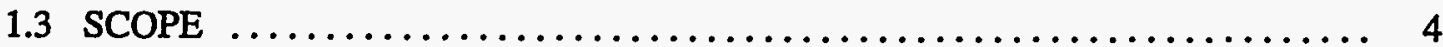

2. HEAT CONDUCTION ANALYSIS OF VESSEL WALL $\ldots \ldots \ldots \ldots \ldots \ldots \ldots$

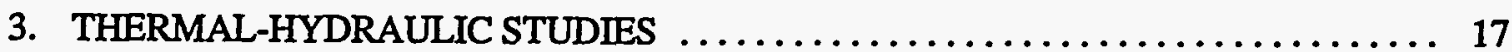

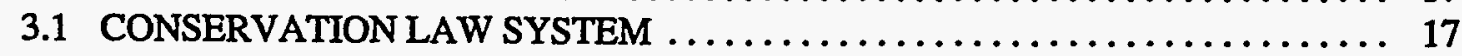

3.22 -D AXISYMMETRIC MODEL DESCRIPTION $\ldots \ldots \ldots \ldots \ldots \ldots \ldots \ldots \ldots \ldots \ldots \ldots$

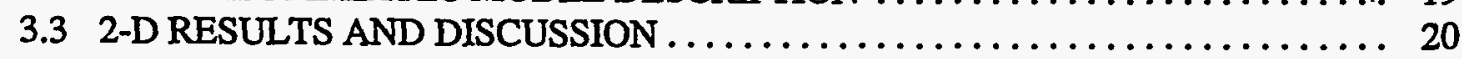

3.3 FUTURE THERMAL-HYDRAULIC STUDIES $\ldots \ldots \ldots \ldots \ldots \ldots \ldots \ldots \ldots \ldots$

4. CONCLUSIONS AND RECOMMENDATIONS $\ldots \ldots \ldots \ldots \ldots \ldots \ldots \ldots \ldots$

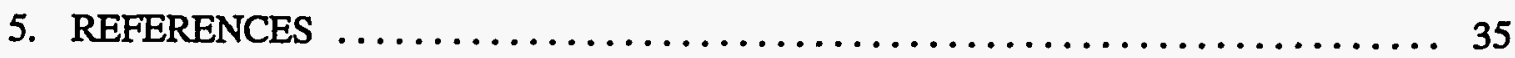




\section{LIST OF FIGURES}

Figure

Page

1 Pressure vs temperature operating envelope for cold source. ................ 3

2 Cross section of ANS cold source with reentrant cavity and inner baffle. .......... 5

3 Mesh layout for HEATING7.2 model of cold source vessel. . . . . . . . . . . . . . . . . . 8

4 Thermal conductivity of $\mathrm{Al} 6063-\mathrm{T} 5$ at cryogenic temperatures. . . . . . . . . . . . 9

5 Neutron heating distribution in cold source vessel wall. . . . . . . . . . . . . . 10

6 Temperature distribution over reactor-side hemisphere of vessel wall for Case 1.1. . . . 12

7 Temperature distribution across backside hemisphere of vessel wall for Case 1.1. ..... 13

8 Forced cooling arrangement for reentrant cavity in Case $1.2 . \ldots \ldots \ldots \ldots \ldots \ldots \ldots$

9 Temperature distribution across reactor-side hemisphere for Case $1.2 \ldots \ldots \ldots \ldots \ldots \ldots$

10 Temperature distribution across backside hemisphere of vessel wall for Case $1.2 . \ldots \ldots 16$

11 Schematic of 2-D axisymmetric cold source model. $\ldots \ldots \ldots \ldots \ldots \ldots \ldots \ldots \ldots \ldots 21$

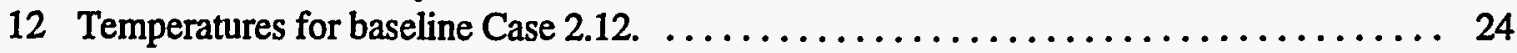

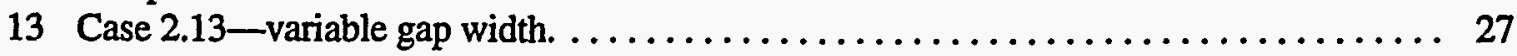

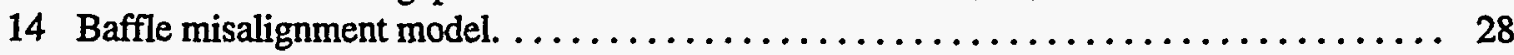

15 Nuclear heating rates for cold source. .......................... 29 


\section{LIST OF TABLES}

Table

Page

1 Engineering design conditions for ANS cold source $\ldots \ldots \ldots \ldots \ldots \ldots \ldots \ldots \ldots \ldots$

2 ANS cold source $2-\mathrm{D}$ axisymmetric model of spherical annulus $\ldots \ldots \ldots \ldots \ldots \ldots \ldots 22$

3 Baffle/vessel misalignment case results. 
<smiles>C[TeH]</smiles> 


\begin{abstract}
The Advanced Neutron Source (ANS), in its conceptual design phase at Oak Ridge National Laboratory, was to be a user-oriented neutron research facility producing the most intense steady-state flux of thermal and cold neutrons in the world. Among its many scientific applications, the production of cold neutrons was a significant research mission for the ANS. The cold neutrons come from two independent cold sources positioned near the reactor core. Contained by an aluminum alloy vessel, each cold source is a 410 -mm-diam sphere of liquid deuterium that functions both as a neutron moderator and a cryogenic coolant. With nuclear heating of the containment vessel and internal baffling, steady-state operation requires close control of the liquid deuterium flow near the vessel's inner surface. Preliminary thermal-hydraulic analyses supporting the cold source design were performed with heat conduction simulations of the vessel walls and multidimensional computational fluid dynamics simulations of the liquid deuterium flow and heat transfer. This report presents the starting phase of a challenging program and describes the cold source conceptual design, the thermal-hydraulic feasibility studies of the containment vessel, and the future computational and experimental studies that were planned to verify the final design.
\end{abstract}





\section{INTRODUCTION}

\subsection{PURPOSE AND OBJECTIVES}

The Advanced Neutron Source (ANS) was intended as a user-oriented neutron research facility producing the most intense flux of thermal and subthermal neutrons in the world. ${ }^{1}$ Representing a significant research mission of the ANS, the production of cold neutron beams was one of many scientific applications for the $330-\mathrm{MW}(f)$ reactor that provided the source of neutrons.

In the ANS conceptual design, cold neutrons are derived from two independent cold sources placed near the reactor core. Each cold source is a 410 -mm-diam sphere of liquid deuterium contained by an aluminum alloy vessel. The liquid deuterium serves both as a neutron moderator and a single-phase cryogenic coolant for the containment vessel. For each cold source, neutron and gamma bombardment produces a heat load of $\sim 15 \mathrm{~kW}$ in the liquid deuterium and an additional $15 \mathrm{~kW}$ in the vessel. The objective is to keep the pressurized cryogen, circulating through the cold source, free from boiling under normal operation and to maintain a minimum temperature as low as practicable with a liquid flow rate of $6.5 \mathrm{~L} / \mathrm{s}(-1.0 \mathrm{~kg} / \mathrm{s})$. The temperature of the liquid deuterium supplied to the vessel is $20 \mathrm{~K}(1.3 \mathrm{~K}$ above the triple point); the deuterium exit temperature is $25 \mathrm{~K}$ ( $2 \mathrm{~K}$ below the saturation temperature for a minimum system pressure of $0.25 \mathrm{MPa}$ ). Because of these rather narrow margins to the phase change temperatures, careful control of all parameters is vitally important. Consistent control of the cryogen velocity over the entire inner surface of the vessel is necessary because of the requirement to remove $15 \mathrm{~kW}$ of heat from the vessel. This control is achieved by internal baffling, designed to add as low a mass as possible to minimize the heat load.

Experimental flow visualization tests using a surrogate fluid and transparent candidate cold source vessel designs were planned to provide valuable general indications of internal flow behavior. Thermal-hydraulic analyses were also to be performed using two- and three-dimensional (2- and 3-D) numerical simulations. Since published data are limited over the range of interest, an experimental program for the measurement of thermophysical property and heat transfer data was planned to support the computational thermal-hydraulic design studies. It is essential to have the capability to consider two-phase flow as part of the analysis of certain normal and abnormal operational transients. Final verification of the selected design included plans for a full-scale test loop with realistic heat loads and liquid deuterium flows.

\subsection{COLD SOURCE CONCEPTUAL DESIGN}

Many current cold source designs operate as a closed-loop gravity-driven thermosyphon in which the moderator material (e.g., hydrogen or a hydrogen-bearing cryogen) condenses in a heat exchanger, flows by gravity as a subcooled liquid to the moderator vessel, boils in the moderator vessel because of neutronic heating, and returns finally to the condenser as a superheated vapor. There are variants on this principle in which boiling occurs only in the vapor-return piping because of a sufficiently large driving head in the condenser drain line. These systems are practical only 
with low-power applications. Reliability is the primary advantage of thermosyphon systems since they require no mechanical pumps or control valves and are typically self-adjusting to a range of operating loads.

The high heat loads applied to the ANS cold source, however, presented severe design difficulties for a thermosyphon system. To minimize pressure losses, a large vapor-return line would have been required, occupying otherwise heavy-water moderator space resulting in reduced cold neutron yields and increased shielding problems. Therefore, a decision was made to use a flooded single-phase system in which liquid deuterium, pressurized to $0.4 \mathrm{MPa}$, is circulated in a closed loop by a mechanical cryogenic pump. Since operation of the cold source and, therefore, the reactor is dependent on this circulator, it is important to provide redundancy in the design. A second circulator unit will be installed to obtain the necessary redundancy.

Figure 1 shows the proposed operating envelope superimposed on the vapor pressure curve for deuterium. A deuterium flowrate of $6.5 \mathrm{~L} / \mathrm{s}(\sim 1.0 \mathrm{~kg} / \mathrm{s})$ results in a temperature rise of $5 \mathrm{~K}$ across the moderator vessel, bringing the maximum temperature of the liquid to within $2 \mathrm{~K}$ of its saturation temperature $(27 \mathrm{~K}$ ) at the minimum design pressure of $0.25 \mathrm{MPa}$ (see Table 1). The liquid deuterium flows in a closed loop with a storage vessel designed to accommodate expansion when the system is warm. The additional storage volume allows the system to remain at an overall maximum pressure of $0.4 \mathrm{MPa}$ at all times.

Cooldown will always occur with the reactor off, and the remaining heat load on the cold source will amount to no more than $1 \mathrm{~kW}$. The cryogenic circulators will not be used during cooldown, so the loop is designed to promote natural convection. Initially, it might be necessary to circulate the warm deuterium gas until its density has increased enough to promote adequate natural convection. The liquefaction phase of startup requires natural convection to avoid vaporlocking the cryogenic circulator impellers.

Heat transfer must be strictly controlled throughout the cooldown phase to remove the enthalpy of the metal components of the loop and limit the cooldown time to about $24 \mathrm{~h}$. During normal operation when the reactor is at full power and is heating the cold source, the circulating liquid must remove $15 \mathrm{~kW}$ from the deuterium itself and another $15 \mathrm{~kW}$ from the vessel walls to maintain temperature control. It is therefore essential to have adequate heat transfer within the cold source vessel. The necessary forced-convection heat transfer coefficients will be established through internal baffles that provide sufficiently high liquid deuterium velocities next to the inner surface of the containment vessel walls. Figure 2 shows an arrangement in which an inner beryllium baffle shell creates a spherical annulus through which the full liquid flow is forced before circulating through the interior of the cold source sphere. The flow in the cold source interior is strongly 3-D because of the rectangular geometry of the reentrant cavity that partially blocks the interior flow.

The ANS operating cycle, determined by the anticipated burnup rate of the reactor fuel and fuel inventory, is currently estimated at 21 days. During the 4 days required for reactor refueling, the cold source vessel must be heated to $373 \mathrm{~K}$ and recooled to operating conditions. This high temperature is required to anneal the vessel material, to minimize the effects of silicon produced by nuclear transmutation. The heat to raise the vessel temperature will be provided by decay heat immediately following shutdown. To prevent overheating of the vessel, cooled deuterium gas will be circulated through the cold source. 


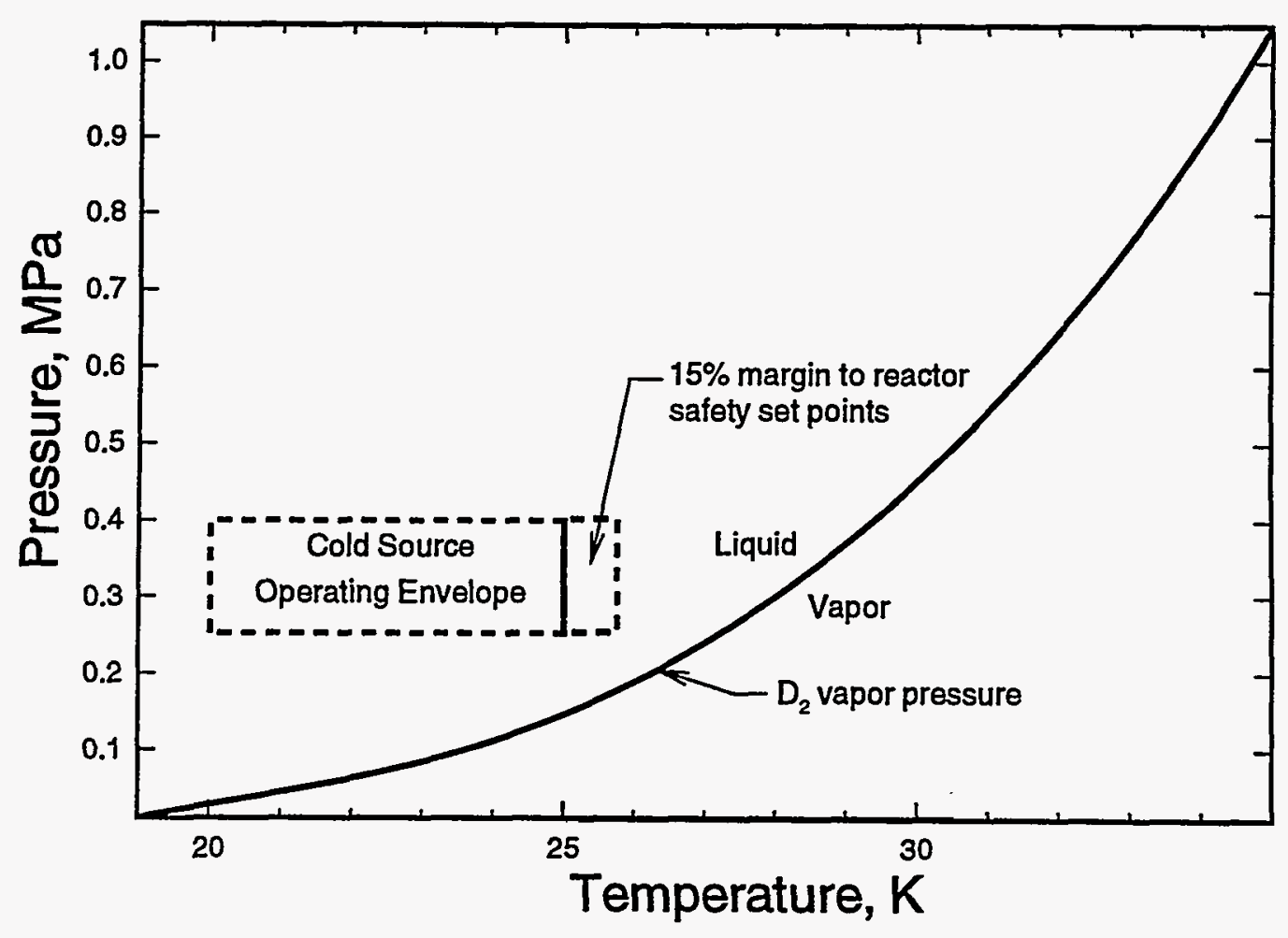

Fig. 1. Pressure vs temperature operating envelope for cold source. 
Table 1. Engineering design conditions for ANS cold source

Moderator/cryogen coolant

Maximum system pressure

Minimum system pressure

Minimum temperature

Maximum temperature

Saturation temperature @ $0.25 \mathrm{MPa}$

Saturation temperature @ $0.4 \mathrm{MPa}$

$\mathrm{D}_{2}$ Triple point

$\mathrm{D}_{2}$ Critical temperature

$\mathrm{D}_{2}$ Critical pressure
Liquid deuterium, $\mathrm{D}_{2}$

$0.4 \mathrm{MPa}$

$0.25 \mathrm{MPa}$

$20 \mathrm{~K}$

$25 \mathrm{~K}$

$27 \mathrm{~K}$

$29 \mathrm{~K}$

$18.7 \mathrm{~K}$

$38.3 \mathrm{~K}$

$1.62 \mathrm{MPa}$

$1.02 \mathrm{~kg} / \mathrm{s}$

\subsection{SCOPE}

This report describes the cold source design concept and the results of initial supporting thermal-hydraulic feasibility studies. The results of a heat conduction analysis of the vessel wall using the HEATING7.2 code is presented in Sect. 2. Section 3 discusses thermal-hydraulic studies of the spherical annulus that provides forced-convection cooling of the cryostat vessel. Both 2-D axisymmetric and proposed 3-D studies are reviewed. Conclusions and recommendations are presented in Sect. 4. 


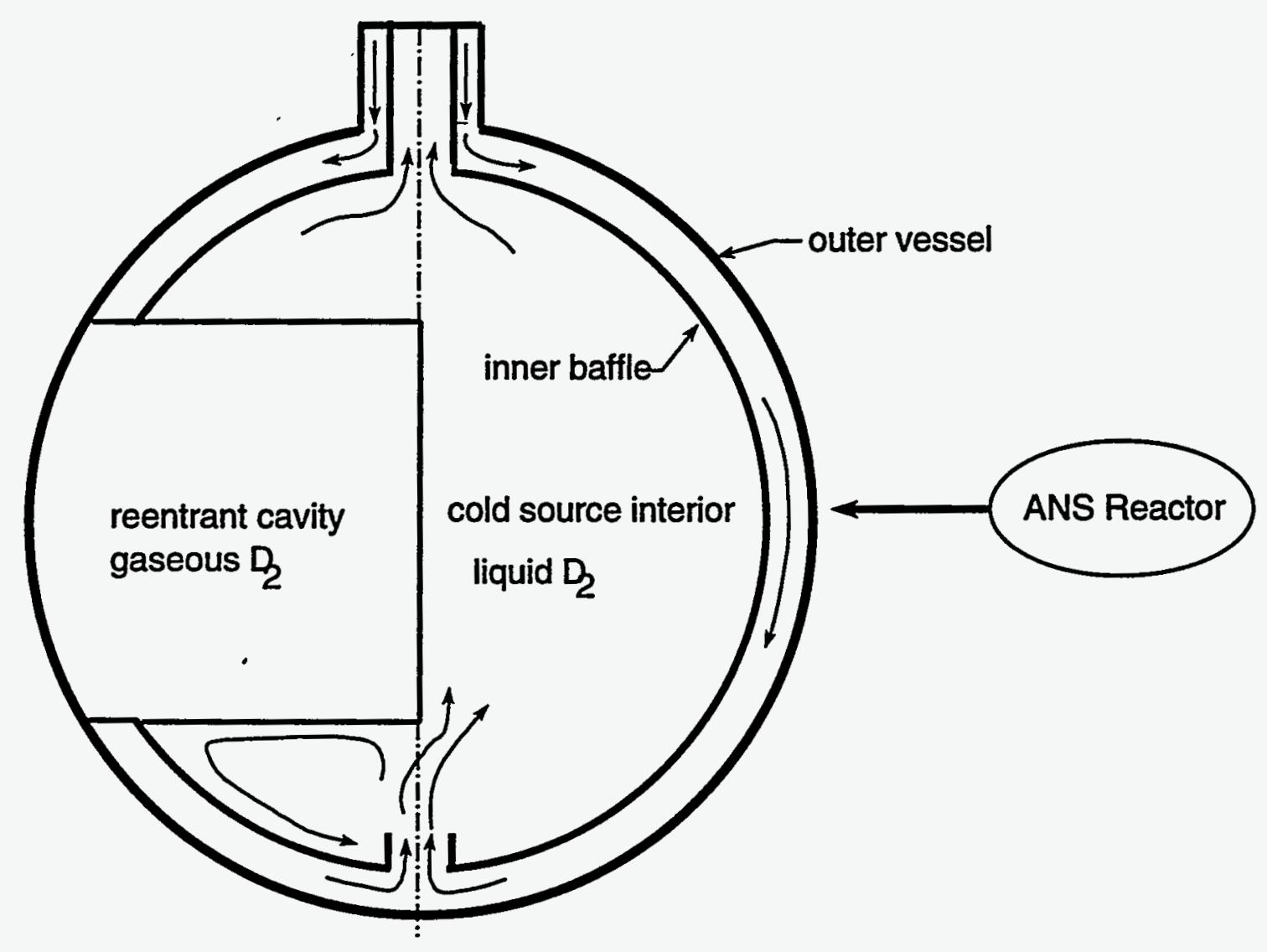

Fig. 2. Cross section of ANS cold source with reentrant cavity and inner baffle. 



\section{HEAT CONDUCTION ANALYSIS OF VESSEL WALX}

In the initial stages of the analysis, a critical issue needed to be resolved. Specifically, how should the reentrant cavity be attached to the inner wall of the cold source vessel? The original design concept provided for a simple attachment in which the cryostat wall itself established the outer boundary or "backside" of the reentrant cavity, as shown in Fig. 2. Since the entire vessel experiences some degree of neutronic heating, an analysis was required to determine if heat conduction within the wall and natural convection to the $\mathrm{D}_{2}$ gas that fills the reentrant cavity would be sufficient to maintain temperature control and prevent localized boiling of the liquid $\mathrm{D}_{2}$ circulating through the cold source.

A heat conduction model of the cold source vessel wall was developed using the HEATING7.2 code. ${ }^{2}$ The mesh, shown in Fig. 3, uses 6272 finite volumes to approximate the geometry of the complete 1.5 -mm-thick spherical aluminum shell. Thermal conductivity data for aluminum at cryogenic temperatures ranging from $4 \mathrm{~K}$ to $120 \mathrm{~K}$ were obtained from Touloukian et $\mathrm{al}^{3}{ }^{3}$ (see Fig. 4). With the origin of the $x-y-z$ rectangular Cartesian coordinate system located at the center of the sphere, the positive $y$-axis passes through the centerline of the ANS reactor. The distribution of neutronic heating in the cold source vessel was approximated by a linear function of $y$, where the maximum heating level of $10 \mathrm{~W} / \mathrm{g}$ occurred at the point on the vessel closest to the reactor, as depicted in Fig. 5. The minimum neutronic heating level of $3.7 \mathrm{~W} / \mathrm{g}$ was located at the point on the vessel farthest from the reactor, that is, diametrically opposite the location of the maximum heating level. With this distribution, the total neutronic heating load on the cold source vessel wall was $15 \mathrm{~kW}$.

For Case 1.1, the boundary conditions were an adiabatic wall for the outer radius of the spherical shell and forced convection cooling to a $20 \mathrm{~K}$ heat sink applied to the inner radius except for that portion of the vessel contiguous to the reentrant cavity where natural convection cooling to a $25 \mathrm{~K}$ heat sink was employed. A forced-convection heat transfer coefficient, $h$, was calculated for fully developed turbulent internal flow $(\operatorname{Re}>10,000)$ from the Dittus-Boelter correlation ${ }^{4}$

$$
h=0.023 \frac{k_{f}}{D_{h}} \operatorname{Re}^{0.8} \operatorname{Pr}^{0.4},
$$

where Re and Pr are the Reynolds and Prandtl numbers defined by

and

$$
\operatorname{Re}=\frac{\dot{m} D_{h}}{A_{x} \mu_{f}}
$$

$$
\operatorname{Pr}=\frac{\mu_{f} c_{p}}{k_{f}},
$$

and $\dot{m}, D_{h}, \mu_{f}, c_{p}$, and $k_{f}$ are the total mass flow rate, hydraulic diameter, liquid dynamic viscosity, specific heat, and thermal conductivity respectively. The cross-sectional flow area, $A_{x}$, varies with the position $z$ by 


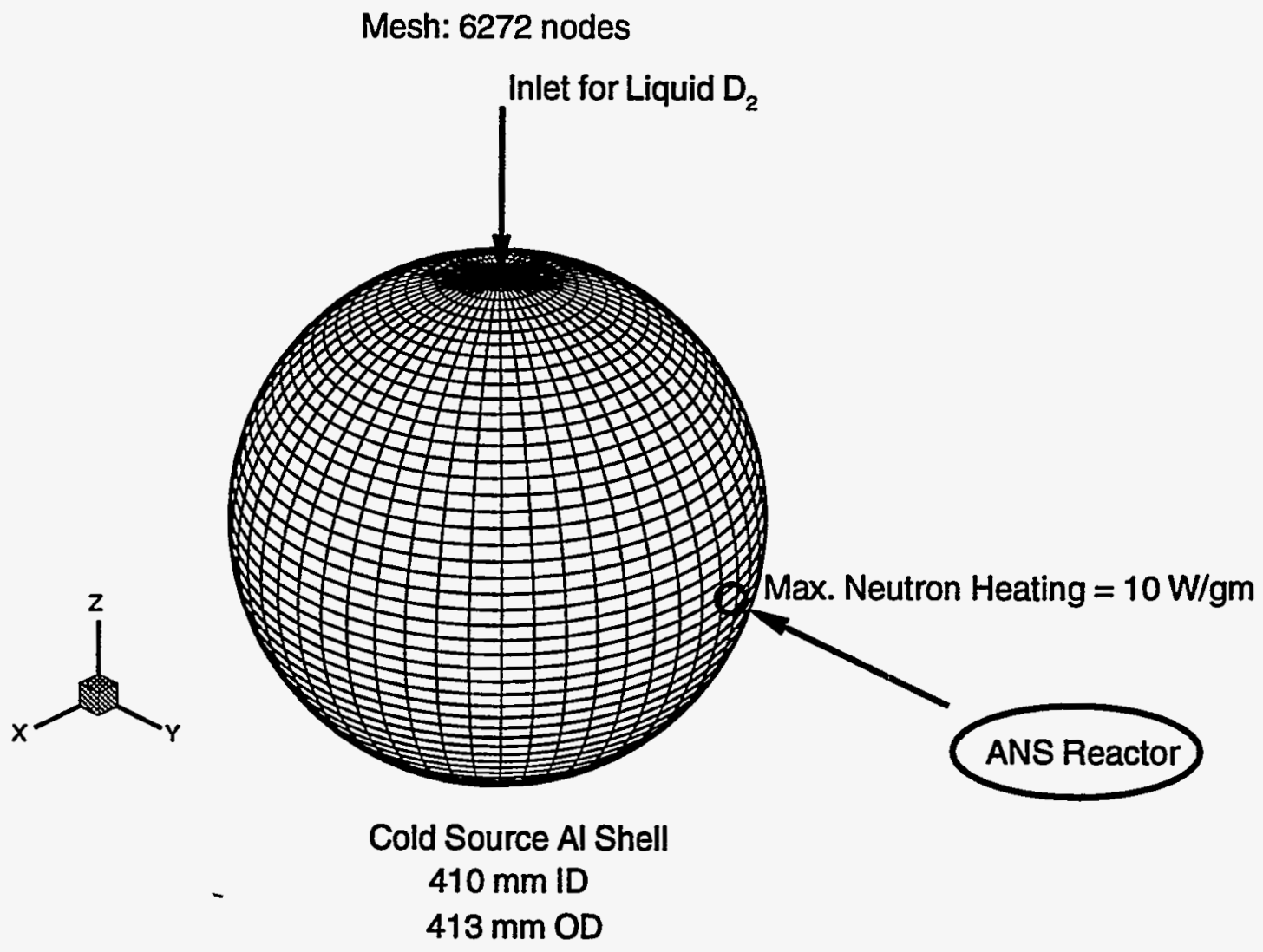

Fig. 3. Mesh layout for HEATING7.2 model of cold source vessel. 


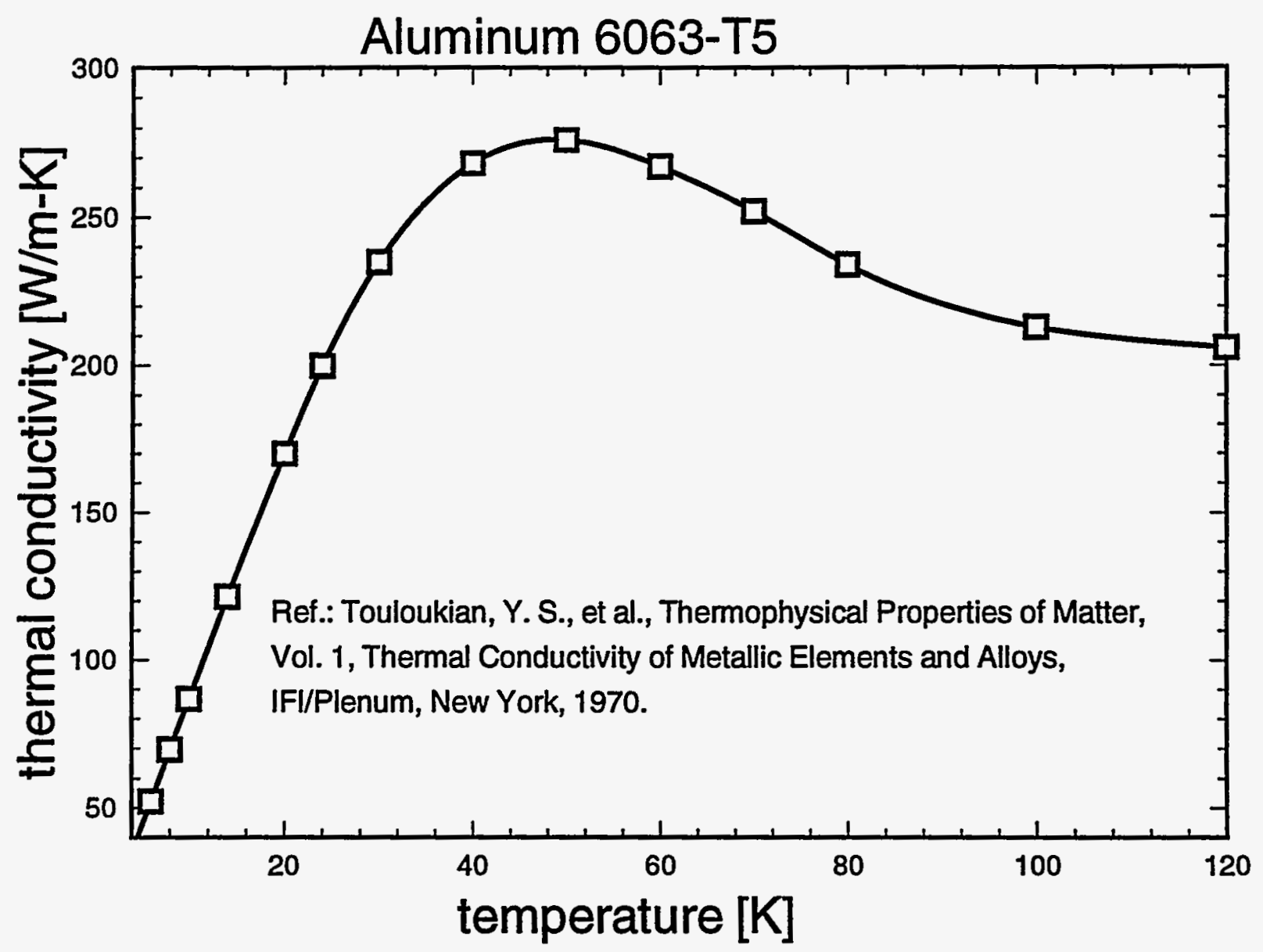

Fig. 4. Thermal conductivity of Al 6063-T5 at cryogenic temperatures. 


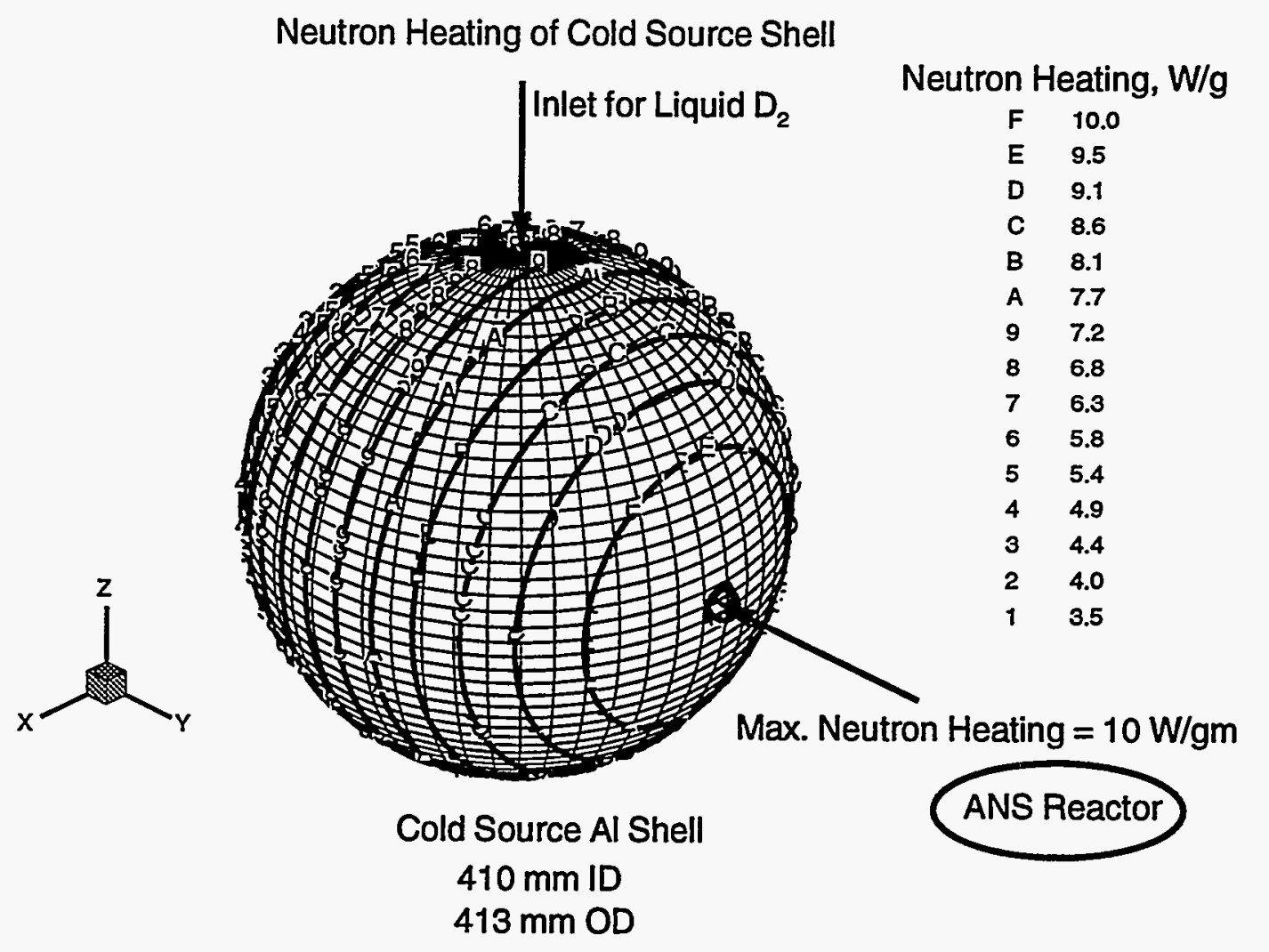

Fig. 5. Neutron heating distribution in cold source vessel wall. 


$$
\begin{aligned}
A_{x}(\Theta) & =\pi \cos (\Theta)\left(205^{2}-203^{2}\right),\left[\mathrm{mm}^{2}\right] \\
\Theta & =\arcsin \left(\frac{z}{204}\right) .
\end{aligned}
$$

Heat transfer coefficients for turbulent natural convection from the vessel wall into the reentrant cavity were calculated with a correlation presented on p. 172 of ref. 4 .

$$
h=0.13 \frac{k_{f}}{L}(\mathrm{Gr} \mathrm{Pr})^{1 / 3},
$$

where $\mathrm{Gr}$ is the Grashof number defined by

$$
\mathrm{Gr} \equiv \frac{p_{f}^{2} g \beta\left(T_{\text {wall }}-T_{\infty}\right) L^{3}}{\mu_{f}^{2}} ; 10^{9}<\mathrm{Gr} \operatorname{Pr}<10^{12}
$$

and $\rho_{f}, g, \beta$, and $L$ are the liquid density, magnitude of the acceleration of gravity, the coefficient of isobaric volume expansion, and the cavity height respectively.

The temperature solution for Case 1.1 is shown in Fig. 6 for the reactor side of the vessel and in Fig. 7 for the far side of the cold source. The maximum vessel temperature for this case was $52.3 \mathrm{~K}$, located in the center of the thermal "footprint" of the reentrant cavity evident in Fig. 7. In Case 1.2, the spherical annulus was extended to provide forced convection cooling to all sides of the reentrant cavity as shown in Fig. 8. The resulting solution for Case 1.2 is depicted in Figs. 9-10. As observed in Fig. 10, the distinctive thermal footprint of the reentrant cavity has been removed. The maximum vessel wall temperature is $28.3 \mathrm{~K}$ for Case 1.2. Based on the results of these scoping calculations, the decision was made to incorporate into the cold source design the requirement that the reentrant cavity should be mounted inside the cold source so that active forced cooling for all sides of the cavity is available. 


\section{HEATING7.2 Case 1 Solution}

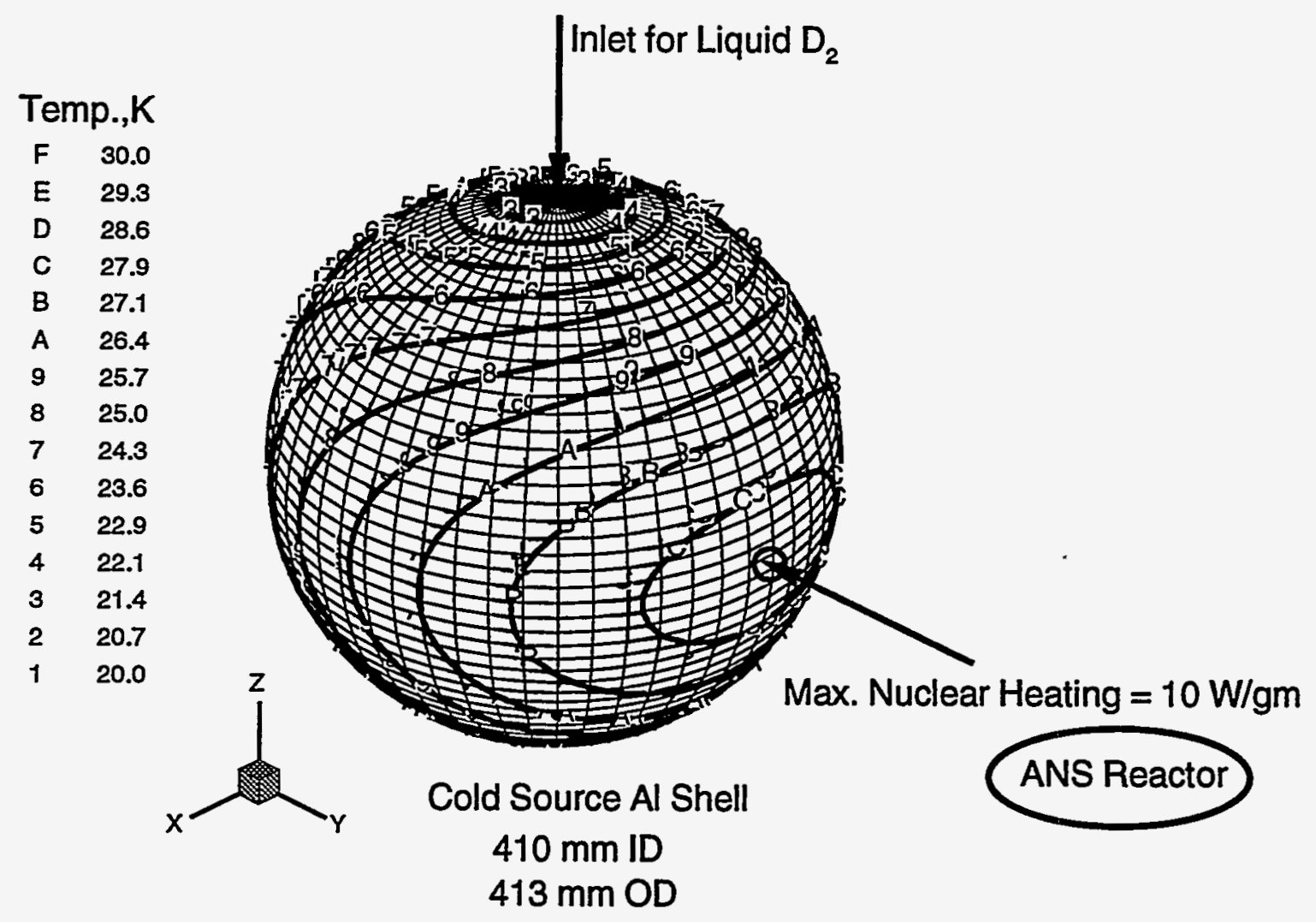

Fig. 6. Temperature distribution over reactor-side hemisphere of vessel wall for Case 1.1. 
HEATING7.2 Case 1 Solution

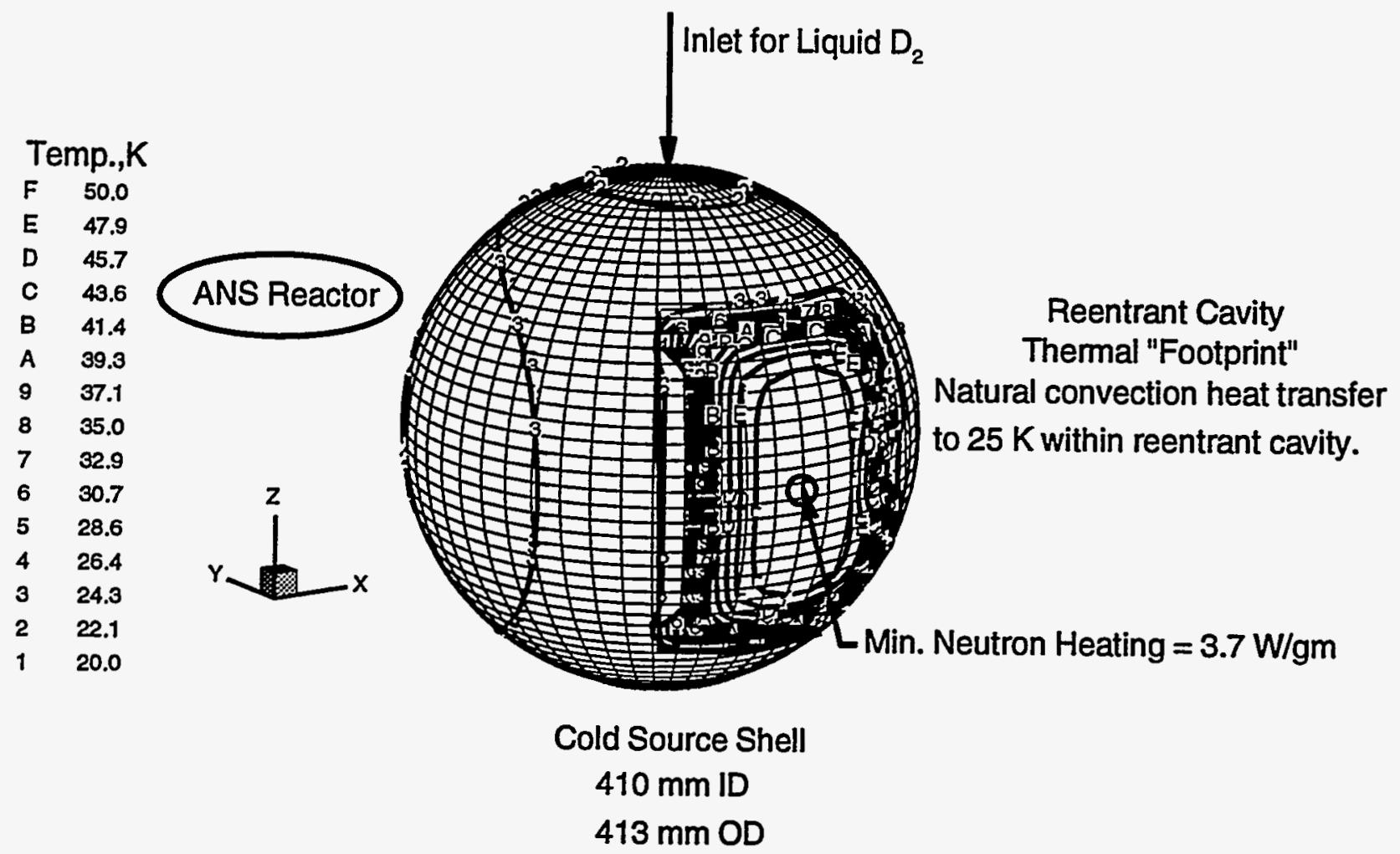

Fig. 7.Temperature distribution across backside hemisphere of vessel wall for Case 1.1. 


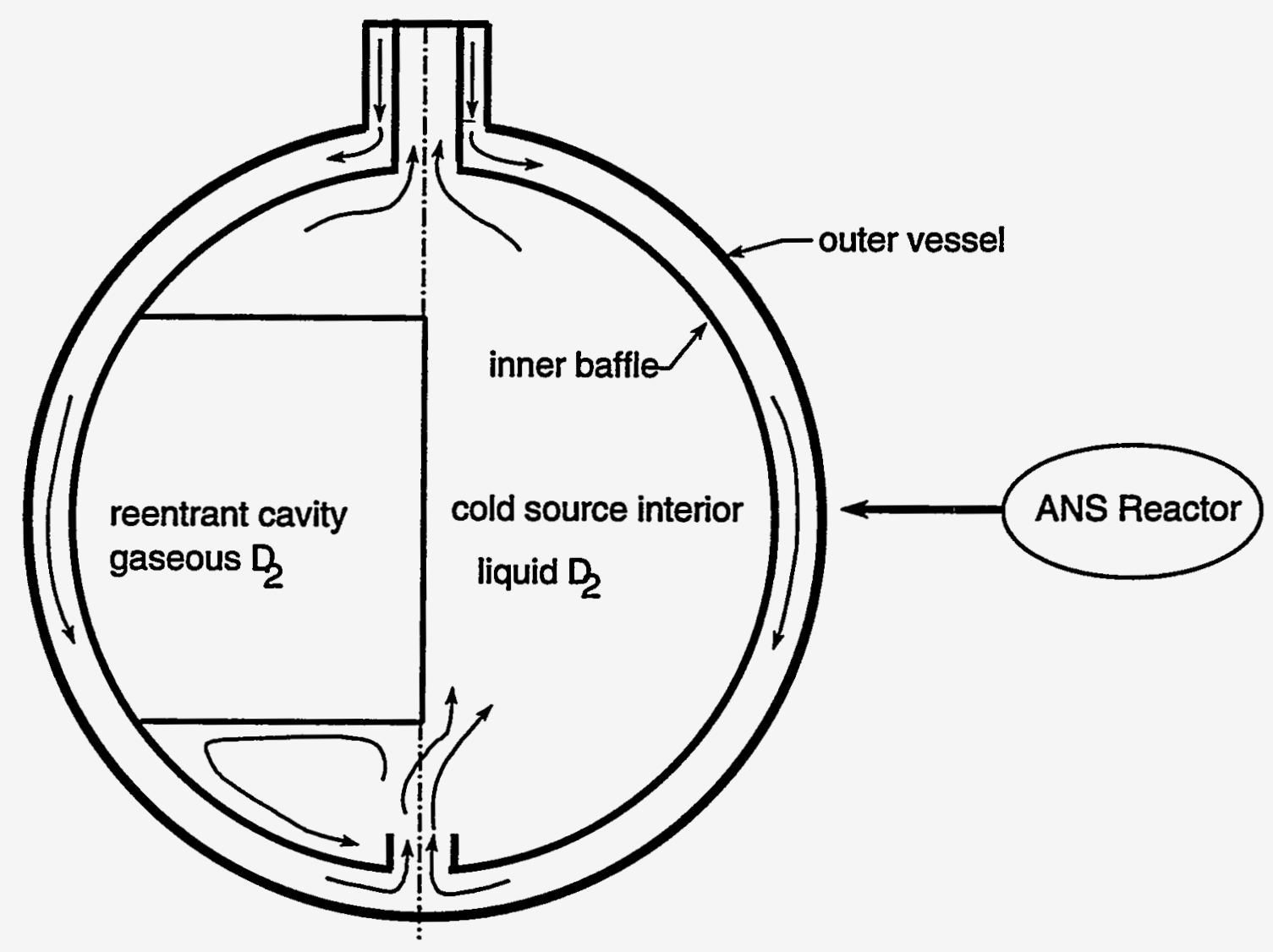

Fig. 8. Forced cooling arrangement for reentrant cavity in Case 1.2. 


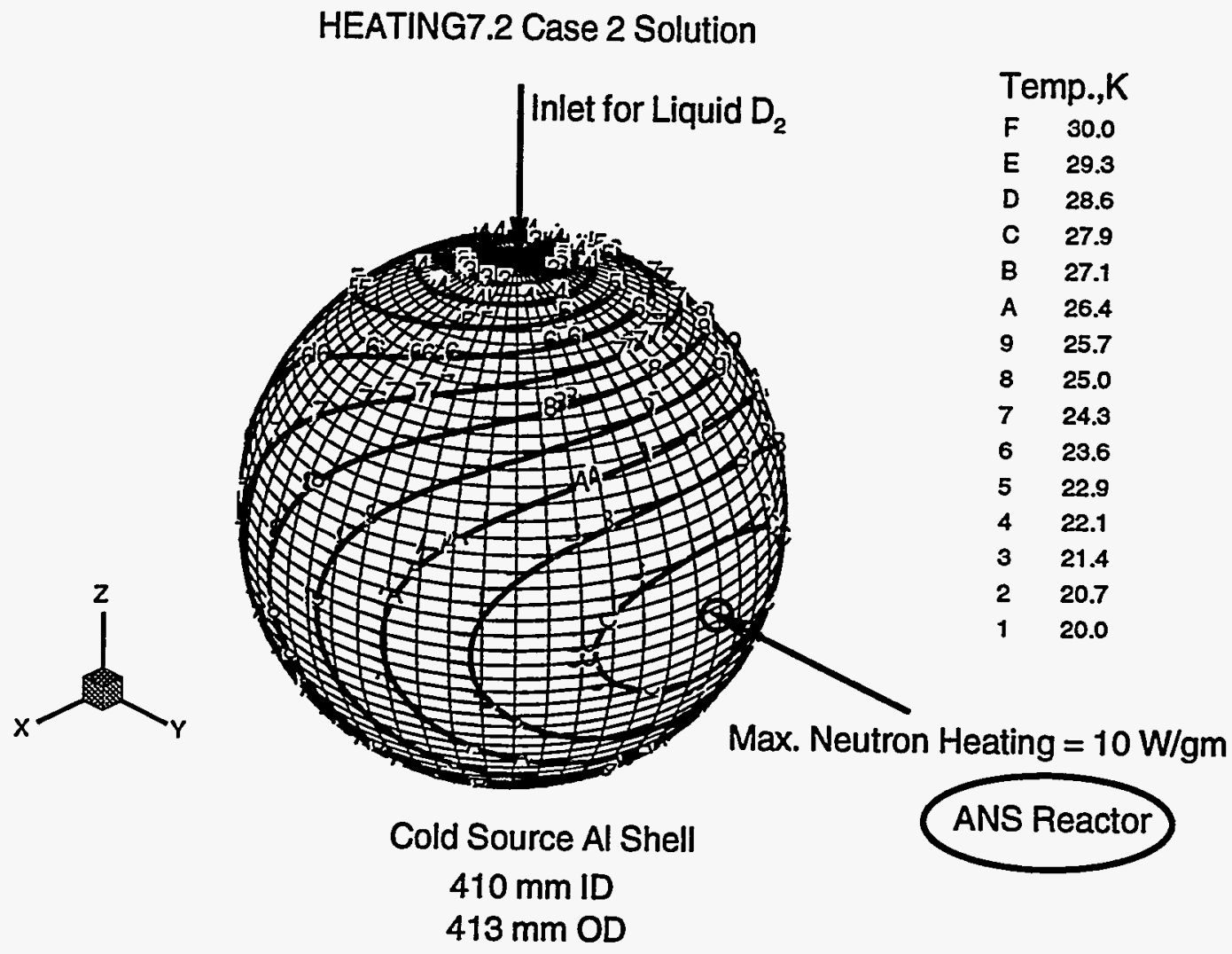

Fig. 9. Temperature distribution across reactor-side hemisphere for Case 1.2. 
HEATING7.2 Case 2 Solution

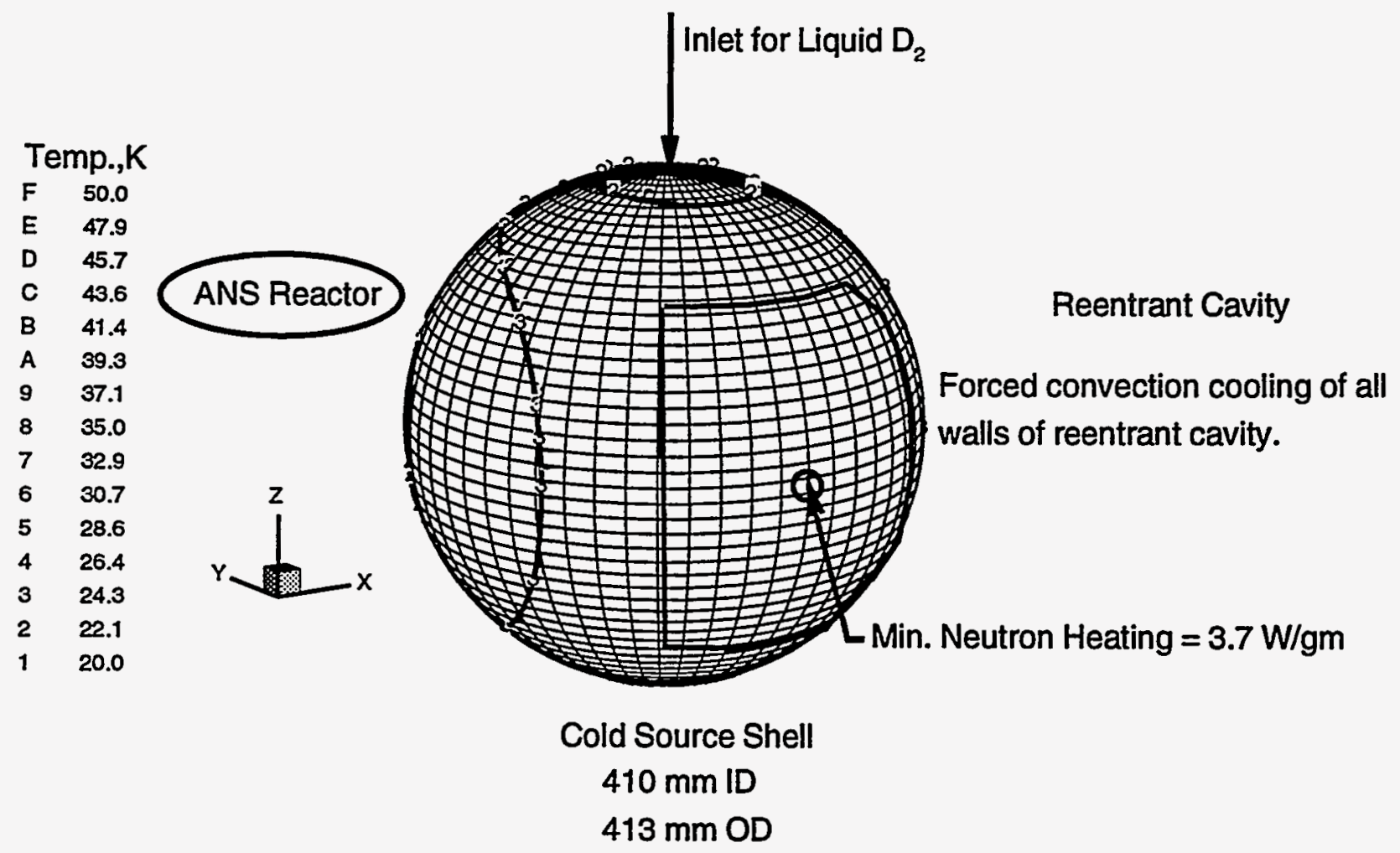

Fig. 10. Temperature distribution across backside hemisphere of vessel wall for Case 1.2. 


\section{THERMAL-HYDRAULIC STUDIES}

\subsection{CONSERVATION LAW SYSTEM}

The turbulent flow of a liquid cryogen with internal heat generation is governed by the physical principles of conservation of mass, momentum, and energy. An appropriate mathematical form for this conservation law system is the coupled set of nonlinear partial differential equations called the Reynolds-averaged Navier-Stokes equations for an incompressible (constant density) fluid. ${ }^{5}$ Using index notation, steady-state forms for the conservation of mass, momentum, and energy are the continuity equation

the momentum equations,

$$
\frac{\partial U_{j}}{\partial x_{j}}=0
$$

$$
\frac{\partial}{\partial x_{j}}\left[\rho U_{i} U_{j}-\mu\left(\frac{\partial U_{i}}{\partial x_{j}}+\frac{\partial U_{j}}{\partial x_{i}}\right)+\rho \overline{u_{i}^{\prime} u_{j}^{\prime}}\right]+\nabla p=0,
$$

and the energy equation,

$$
\frac{\partial}{\partial x_{j}}\left(\rho U_{j} H-\rho \alpha \frac{\partial H}{\partial x_{j}}+\rho \overline{u_{j}^{\prime} h^{\prime}}\right)-S_{H}=0,
$$

where $\rho, \mu$, and $\alpha$ are the density, molecular dynamic viscosity, and molecular thermal diffusivity, respectively, of the fluid; $U_{i}$ is the time-averaged velocity vector resolution of the mean flow field; $H$ is the time-averaged static enthalpy; $p$ is the motion pressure (equal to the thermostatic pressure minus the hydrostatic pressure); and $S_{H}$ represents any distributed volumetric heat sources. Repeated indices imply summation over the computational domain, $\mathbf{R}^{\mathrm{n}}$. In CFDS-FLOW3D, Eqs. (6)-(8) are discretized using a nonstaggered finite volume method, and steady-state solutions for the discrete equation set are calculated using the SIMPLEC algorithm. ${ }^{6}$

Arising from the time-averaging of the convection terms in the original instantaneous conservation law system, statistical double correlations appear in Eqs. (7) and (8) that characterize the effects of turbulence on the transport of momentum (Reynolds stresses, $\rho \overline{u_{i}^{\prime} u_{j}^{\prime}}$ ) and thermal energy (turbulent heat fluxes, $\rho \overline{u_{i}^{\prime} h^{\prime}}$ ) in the mean flow field. Transport equations for each of these double correlations can be derived, but these new equations unfortunately contain additional unknown higher order correlations; therefore, Eqs. (6)-(8) do not represent a closed set. An exact closure for these correlations does not exist. The result is the classic turbulence closure problem, and approximate closure is the task of turbulence models.

For engineering calculations, the most commonly used turbulence models are based upon the Boussinesq eddy-viscosity approximation, where the Reynolds stresses are modeled by a constitutive relation having a form similar to the Stokes viscosity law for Newtonian fluids, 


$$
-\rho \overline{u_{i}^{\prime} u_{j}^{\prime}}=-\frac{2}{3} \rho \kappa \delta_{i j}+\mu_{T}\left(\frac{\partial U_{i}}{\partial x_{j}}+\frac{\partial U_{j}}{\partial x_{i}}\right) \text {, }
$$

where $\kappa$ is the turbulent kinetic energy per unit mass $\left(\kappa=u_{\mathrm{i}}{ }^{\prime} u_{\mathrm{i}}{ }^{\prime} / 2\right), \delta_{\text {if }}$ is the Kronecker delta, and $\mu_{\mathrm{T}}$ is the eddy viscosity. Similar eddy diffusivity hypotheses, coupled with Reynolds-analogy approximations, result in constitutive relations for the turbulent heat flux

$$
-\rho \overline{u_{i}^{\prime} h^{\prime}}=\Gamma_{H} \frac{\partial H}{\partial x_{i}}=\frac{\mu_{T}}{\sigma_{H}} \frac{\partial H}{\partial x_{i}},
$$

where $\Gamma_{H}$ is the thermal eddy diffusivity and $\sigma_{H}$ is the turbulent Prandtl number. Equations (9)-(10) represent defining relations for the eddy viscosity and eddy diffusivities. A method for calculating these quantities remains to be identified to obtain closure.

From dimensional arguments, turbulence models based on the Boussinesq approximation, Eq. (9), assume that the eddy viscosity is proportional to the product of length and velocity scales that are characteristic of the turbulence. The two-equation $k-\epsilon$ ( $\epsilon$ is the isotropic turbulence dissipation rate) turbulence model uses the Prandtl-Kolmogorov equation,

$$
\mu_{T}=C_{\mu} \rho \frac{\kappa^{2}}{\epsilon},
$$

where $C_{\mu}$ is an empirically derived constant, to relate $\kappa$ and $\epsilon$ to the eddy viscosity, $\mu_{\tau}$. The velocity scale is $\sqrt{\kappa}$, and the characteristic length scale is $\kappa^{3 / 2} / \epsilon$. Transport equations for $\kappa$ and $\epsilon$ are solved to complete the approximate turbulence closure,

$$
\begin{gathered}
\frac{\partial \rho U_{j} \kappa}{\partial x_{j}}-\frac{\partial}{\partial x_{j}}\left[\left(\mu+\frac{\mu_{T}}{\sigma_{\kappa}}\right) \frac{\partial \kappa}{\partial x_{j}}\right]-\left(\mu+\mu_{T}\right) \frac{\partial U_{i}}{\partial x_{j}}\left(\frac{\partial U_{i}}{\partial x_{j}}+\frac{\partial U_{j}}{\partial x_{i}}\right)+\rho \epsilon=0, \\
\frac{\partial \rho U_{j} \epsilon}{\partial x_{j}}-\frac{\partial}{\partial x_{j}}\left[\left(\mu+\frac{\mu_{T}}{\sigma_{\epsilon}}\right) \frac{\partial \epsilon}{\partial x_{j}}\right]-C_{1} \frac{\epsilon}{\kappa}\left(\mu+\mu_{T}\right) \frac{\partial U_{i}}{\partial x_{j}}\left(\frac{\partial U_{i}}{\partial x_{j}}+\frac{\partial U_{j}}{\partial x_{i}}\right)+C_{2} \rho \frac{\epsilon^{2}}{\kappa}=0,
\end{gathered}
$$

where $\sigma_{\mathrm{x}}, \sigma_{\epsilon}, C_{l}$, and $C_{2}$ are empirically derived constants. In the standard high-Reynolds number $\kappa-\epsilon$ model, the computational domain does not extend all the way to solid walls. So-called wall functions, derived from the logarithmic "law-of-the-wall" velocity profile, are employed to simulate the effect of the no-slip wall boundary condition on the flow field adjacent to the wall. Related heat flux wall functions are also available for the energy equation to calculate the heat transfer between the flow domain and solid boundaries.?

The Boussinesq approximation, Eq. (9), assumes that the eddy viscosity is isotropic, that is, the eddy viscosity is the same for all components of the Reynolds stress tensor. This assumption prevents eddy viscosity turbulence models from predicting certain turbulence-induced secondary flows. One approach to calculating approximations for the Reynolds stresses and turbulent heat fluxes that does not involve the eddy viscosity hypothesis is to derive transport differential equations for the individual components of the Reynolds stresses, using modeled terms to approximate the higher-order correlations to obtain 


$$
\frac{\partial}{\partial x_{k}}\left(\rho \overline{u_{i}^{\prime} u_{j}^{\prime}} U_{k}\right)-\frac{\partial}{\partial x_{k}}\left(\rho \frac{C_{s}}{\sigma_{D S}} \frac{\kappa}{\epsilon} \overline{u_{i}^{\prime} u_{l}^{\prime}} \frac{\partial \overline{u_{k}^{\prime} u_{j}^{\prime}}}{\partial x_{l}}\right)-P_{i j}-\Phi_{i j}+\frac{2}{3} \rho \epsilon \delta_{i j}=0,
$$

where $P_{i j}$ is the shear-stress-production tensor,

$$
P_{i j}=-\rho\left(\overline{u_{i}^{\prime} u_{k}^{\prime}} \frac{\partial U_{j}}{\partial x_{k}}+\frac{\partial U_{i}}{\partial x_{k}} \overline{u_{k}^{\prime} u_{j}^{\prime}}\right),
$$

and $\Phi_{i j}$ is the pressure-strain tensor,

$$
\Phi_{i j} \equiv-\rho C_{1 s} \frac{\epsilon}{\kappa}\left(\overline{u_{i}^{\prime} u_{j}^{\prime}}-\frac{2}{3} \kappa \delta_{i j}\right)-C_{2 s}\left(P_{i j}-\frac{1}{3} P_{k k} \delta_{i j}\right) \text {. }
$$

In addition to the differential transport equations for the Reynolds stress tensor components and the dissipation rate $\epsilon$, the differential Reynolds-flux turbulence model (DFM) solves a transport equation for the Reynolds turbulent heat flux, $\rho \overline{u_{i}^{\prime} h^{\prime}}$, the statistical double correlation between the velocity fluctuations and the fluctuating instantaneous static enthalpy, $h^{\prime}$,

$$
\frac{\partial}{\partial x_{j}}\left(\rho \overline{u_{i}^{\prime} h^{\prime}} U_{j}\right)-\frac{\partial}{\partial x_{k}}\left(\rho \frac{C_{s}}{\sigma_{D F}} \frac{\kappa}{\epsilon} \overline{u_{i}^{\prime} u_{j}^{\prime}} \frac{\partial \overline{u_{k}^{\prime} h^{\prime}}}{\partial x_{j}}\right)-P_{F i}-\pi_{i}=0,
$$

where $P_{F I}$ is the mean-field-production vector,

$$
P_{F i} \equiv-\rho\left(\overline{u_{i}^{\prime} u_{j}^{\prime}} \frac{\partial H}{\partial x_{j}}+\frac{\partial U_{i}}{\partial x_{j}} \overline{u_{j}^{\prime} h^{\prime}}\right),
$$

and $\pi_{i}$ is a pressure-scalar gradient term,

$$
\pi_{i}=-\rho C_{1 F} \frac{\epsilon}{\kappa} \overline{u_{i}^{\prime} h^{\prime}}-\rho C_{2 F} \frac{\partial U_{i}}{\partial x_{j}} \overline{u_{j}^{\prime} h^{\prime}}
$$

The model constants in Eqs. (14)-(19), $\dot{\sigma}_{D S}, \sigma_{D F}, C_{s}, C_{l s}, C_{2 s}, C_{I F}$, and $C_{2 F}$, are assigned default values as discussed in ref. 5 , and wall functions are applied to connect the computational domain to solid wall boundaries. Additional wall-reflection terms are included in the pressure-scalar gradient vector $\pi_{i}$ as discussed by Clarke and Wilkes. ${ }^{8}$ Both the two-equation $k-\epsilon$ model and the DFM were used in the sensitivity studies discussed in the next section.

\subsection{2-D AXISYMMETRIC MODEL DESCRIPTION}

During the conceptual design phase of the cold source, the thermal-hydraulic studies have focused on determining the feasibility of using single-phase forced convection to remove the $30 \mathrm{~kW}$ of heat 
generated by neutron and gamma bombardment of the containment vessel and liquid deuterium during normal steady-state operation. The necessary forced-convection heat transfer at the inner surface of the containment vessel is accomplished by directing the recirculating liquid deuterium, as it first enters the cold source, through a spherical annulus formed by an internal beryllium baffle and the aluminum containment vessel wall. This annulus was modeled, using the computational fluid dynamics (CFD) computer program CFDS-FLOW3D, with a hemispheric 2-D axisymmetric geometry for the half of the cold source sphere near the reactor. The model included internal heat generation and conduction within the 1.5-mm-thick aluminum shell and the 1-mm-thick beryllium inner baffle, as well as internal heat generation, turbulent flow, and heat transfer within the 2-mm-wide liquid deuterium annular flow field. A schematic of the model is shown in Fig. 11, where the computational domain includes the 38-mm-ID inlet pipe, the aluminum containment vessel, the beryllium baffle, the spherical annulus, and the outlet transition into the interior of the cold source. The cold source interior was not explicitly included in the model, but its influence on heat transfer in the annulus was approximated with a constant heat transfer coefficient and cold source interior $\mathrm{D}_{2}$ temperature, $T_{*}$, applied to the inner wall of the baffle.

For a design volumetric flowrate of $6.5 \mathrm{~L} / \mathrm{s}$, the Reynolds number, $\mathrm{Re}$, of the liquid deuterium in the annulus varies from a maximum of approximately $2.5 \times 10^{5}$ near the inlet and outlet transitions to a minimum of approximately $5 \times 10^{4}$ at the equator. This Reynolds number range (where $R e \equiv$ $\left.G_{b} D_{h} / \mu\right)$ is based on the local mass flux, $G_{b}=\dot{m} /\left[\pi \cos \theta\left(205^{2}-203^{2}\right)\right]$, where $\dot{m}$ is the total mass flowrate, $\theta$ is defined in Fig. 11, and the hydraulic diameter of the annulus, $D_{h}=\left(D_{o}-D_{i}\right)=4 \mathrm{~mm}$, is representative of fully developed turbulent flow in interior channels. Deviations from fully developed velocity and temperature profiles should be expected, however, in channel transition regions.

Thermophysical properties (thermal conductivity, density, and specific heat) for aluminum and beryllium were taken from Touloukian et al. (ref. 3) for the cryogenic temperature range of interest, $20-30 \mathrm{~K}$. The results of an extensive literature survey of property data (dynamic viscosity, density, specific heat, and thermal conductivity) for liquid deuterium by Bass ${ }^{9}$ were also used in the model development.

\subsection{2-D RESULTS AND DISCUSSION}

An initial meshing study was carried out to determine the spanwise resolution required to obtain essentially grid-independent solutions. For a deuterium mass flowrate of $1.02 \mathrm{~kg} / \mathrm{s}$, inlet temperature of $20 \mathrm{~K}$, and a uniform nuclear heating rate of $10.94 \mathrm{~kW}$ in the aluminum vessel hemisphere, steadystate solutions using spanwise discretizations across the annulus of 5,10 , and 15 finite volumes showed only small differences in the pressure drop and temperature distributions for the 10 and 15 volume cross-channel cases. Therefore, all subsequent cases employed 15 finite volumes distributed uniformly across the annulus. The flow path within the annulus was discretized with 200 columns of cross-channel rows nonuniformly graded to concentrate the mesh near the inlet and outlet transition regions. Different gradings were also tested to determine a grid-independent configuration.

The results of 13 steady-state solutions are summarized in Table 2, where the test matrix includes variations in mass flowrate, nuclear heat generation, heat transfer links to the cold source interior, and annulus geometry. Of primary interest are the calculated pressure drop from the $38-\mathrm{mm}-\mathrm{ID}$ inlet to the outlet of the model (at the point of entry into the cold source interior), temperatures of the liquid deuterium, and the wall temperature distributions in the aluminum containment vessel (the outer wall of the annulus) and in the beryllium baffle (the inner wall of the annulus). Both the DFM and $\kappa-\epsilon$ turbulence models were used for the initial test cases, and the DFM consistently predicted maximum wall temperatures $\sim 0.2 \mathrm{~K}$ higher than the $\kappa-\epsilon$ turbulence model. No significant differences 


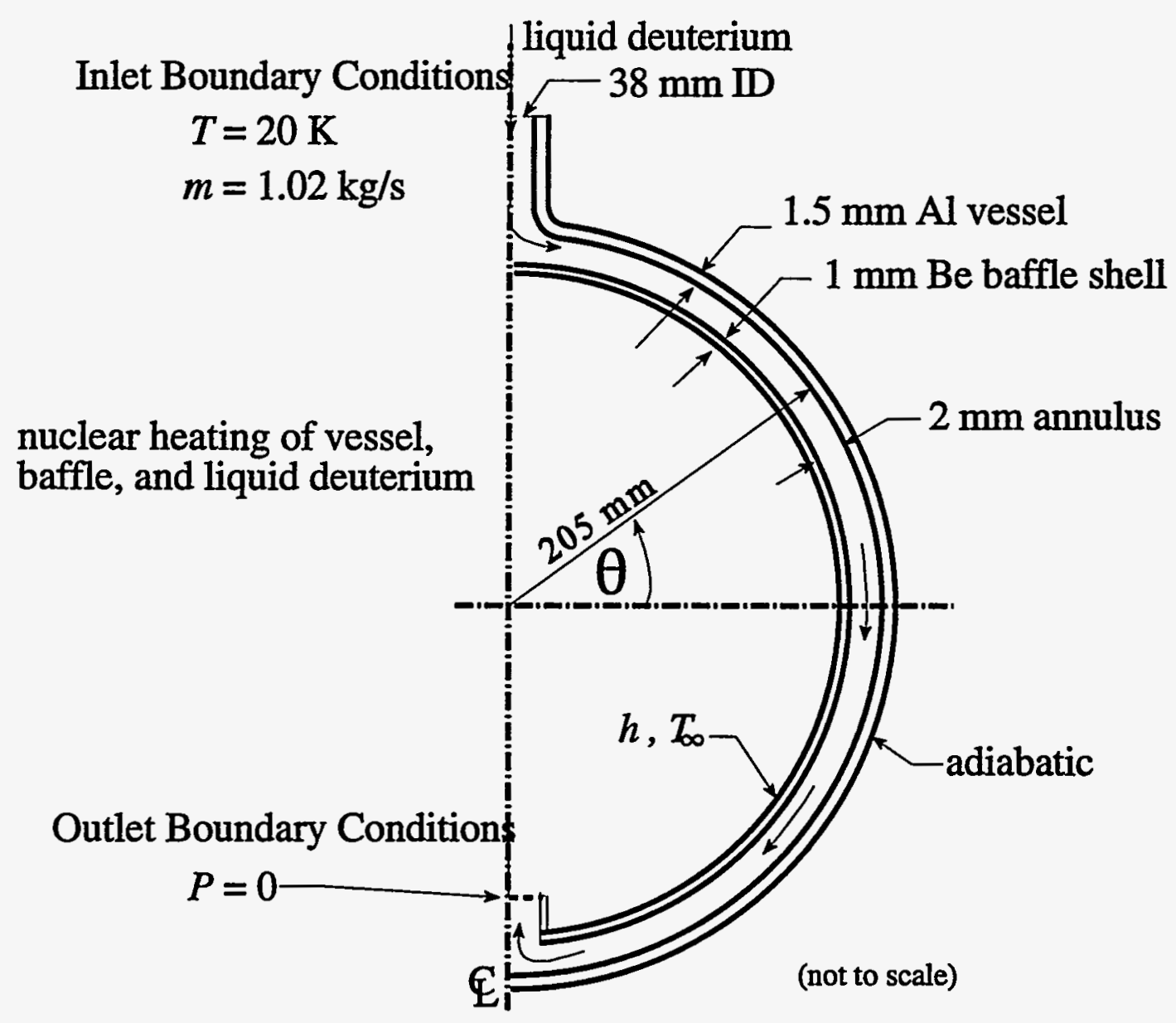

Fig. 11. Schematic of 2-D axisymmetric cold source model. 
Table 2. ANS cold source 2-D axisymmetric model of spherical annulus-reactor-side hemisphere

\begin{tabular}{|c|c|c|c|c|c|c|c|c|c|c|c|c|}
\hline \multirow{3}{*}{ Case } & \multicolumn{3}{|c|}{ Liquid $\mathrm{D}_{2}$} & \multicolumn{6}{|c|}{ Aluminum outer shell and annulus } & \multicolumn{3}{|c|}{ Beryllium shell-inner surface } \\
\hline & \multirow{2}{*}{$\begin{array}{c}\text { Mass flowa } \\
(\mathrm{kg} / \mathrm{s})\end{array}$} & \multirow{2}{*}{$\begin{array}{l}\Delta \mathrm{T}^{b} \\
(\mathrm{~K})\end{array}$} & \multirow{2}{*}{$\begin{array}{c}\operatorname{Max} \Delta P \\
(\mathrm{MPa})\end{array}$} & \multirow{2}{*}{$\begin{array}{c}\text { Heat to } \\
\text { hemisphere } \\
(\mathrm{kW})\end{array}$} & \multirow{2}{*}{$\begin{array}{c}\text { Heat flux } \\
\text { distribution } \\
\left(\mathrm{kW} / \mathrm{m}^{2}\right)\end{array}$} & \multicolumn{4}{|c|}{ At max. Al shell temperature location } & \multicolumn{3}{|c|}{ At max. Al shell temperature location } \\
\hline & & & & & & $\begin{array}{l}T_{\text {wall }} \\
(\mathrm{K})\end{array}$ & $\begin{array}{c}\Delta T_{\text {super. }}{ }^{c} \\
(\mathrm{~K})\end{array}$ & $\begin{array}{c}T_{\text {fouler }} \\
(\mathrm{K})\end{array}$ & $\begin{array}{l}\mathrm{T}_{\text {finner }} \\
(\mathrm{K})\end{array}$ & $\begin{array}{c}\mathrm{h} \\
\left(\mathrm{W} / \mathrm{m}^{2}-\mathrm{K}\right)\end{array}$ & $\begin{array}{l}\mathrm{T} \infty \\
(\mathrm{K}) \\
\end{array}$ & $\begin{array}{l}\mathrm{T}_{\mathrm{Be}} \\
(\mathrm{K})\end{array}$ \\
\hline 2.1 & 0.51 & 3.6 & 0.10675 & 10.94 & 41.6 & 29.4 & 1.5 & 23.4 & 21.7 & 0 & 25 & 21.7 \\
\hline 2.2 & 0.51 & 3.6 & 0.10675 & 10.94 & $52.8 \cos \theta$ & 30.8 & 2.9 & 23.6 & 21.5 & 0 & 25 & 21.5 \\
\hline 2.3 & 0.612 & 3.0 & 0.15375 & 10.94 & $52.8 \cos \theta$ & 29.6 & 2.5 & 23.2 & 21.3 & 0 & 25 & 21.3 \\
\hline \multicolumn{13}{|c|}{ Curvature ( $7-\mathrm{mm}$ radius) added to junction between supply line and annulus for all of the following cases. } \\
\hline 2.4 & 0.51 & 3.6 & 0.07615 & 10.94 & 41.6 & 29.4 & 1.0 & 23.5 & 21.8 & 150 & 25 & 22.0 \\
\hline 2.5 & 0.51 & 3.6 & 0.07615 & 10.94 & $52.8 \cos \theta$ & 30.8 & 2.4 & 23.6 & 21.6 & 150 & 25 & 21.7 \\
\hline 2.6 & 0.612 & 3.0 & 0.10917 & 10.94 & $52.8 \cos \theta$ & 29.6 & 1.8 & 23.1 & 21.3 & 150 & 25 & 21.5 \\
\hline 2.7 & 0.51 & 4.7 & 0.07615 & 10.94 & $52.8 \cos \theta$ & 31.3 & 3.0 & 24.4 & 23.0 & $\infty$ & 25 & 25.0 \\
\hline 2.8 & 0.51 & 2.5 & 0.07615 & 7.5 & 29.5 & 27.0 & 0.0 & 22.5 & 21.3 & 150 & 25 & 21.5 \\
\hline 2.9 & 0.51 & 2.5 & 0.07615 & 7.5 & 29.5 & 27.0 & 0.0 & 22.5 & 21.4 & 150 & 22.5 & 21.4 \\
\hline \multicolumn{13}{|c|}{ The following two cases have a 3-mm gap. } \\
\hline 2.10 & 0.51 & 3.6 & 0.036 & 10.94 & 41.6 & 32.0 & 3.1 & 23.9 & 21.5 & 150 & 25 & 21.5 \\
\hline 2.11 & 0.51 & 3.6 & 0.036 & 10.94 & $52.8 \cos \theta$ & 33.7 & 4.8 & 24.2 & 21.3 & 150 & 25 & 21.3 \\
\hline \multicolumn{13}{|c|}{ Baseline Case: The following case has the conduction effects in the $\mathrm{Al}$ and Be shells included; a uniform internal heat generation of $1.37 \mathrm{~kW}$ has been added to the Be hemisphere (2.74k W total). } \\
\hline 2.12 & 0.51 & 3.9 & 0.07615 & 10.69 & $51.6 \cos \theta$ & 30.7 & 2.3 & 23.7 & 21.8 & 150 & 25 & 22.9 \\
\hline \multicolumn{13}{|c|}{ The following case has the same heat loads as 2.12 , but the geometry has been modified to include a bulge in the Be shell. This bulge gives a $1-\mathrm{mm}$ gap width at the equator. } \\
\hline 2.13 & 0.51 & 3.9 & 0.07615 & 10.69 & $51.6 \cos \theta$ & 30.6 & 2.2 & 24.6 & 22.6 & 150 & 25 & 22.6 \\
\hline
\end{tabular}

a This is the mass flow through the hemisphere model or one-half of the total liquid deuterium flow through the cold source.

${ }^{b} \Delta \mathrm{T}$ is the temperature rise of the liquid deuterium as it passes through the annulus.

Wall superheat is calculated using a saturation temperature based on the minimum pressure in the annulus. The inlet pressure is $0.4 \mathrm{MPa}$. 
in pressure drop or flow field velocity distributions were observed between the two models. The greater detail available in the DFM may prove to be more important in the 3-D models planned for future studies. All of the results presented in Table 2 were calculated using the DFM.

Pressure drops of from 0.107 to $0.154 \mathrm{MPa}$ were calculated in the first three cases. A significant contributor to the pressure drop in these cases was a flow separation around a sharp reentrant corner in the transition of the flow from the $38-\mathrm{mm}-\mathrm{ID}$ inlet line to the 2-mm annulus. The flow separation was removed by adding a curvature (7-mm radius) to the outer wall geometry in this region, thus emphasizing the importance of smooth transitions in the piping design. For the remaining cases, the pressure drops in the liquid deuterium were approximately $0.08 \mathrm{MPa}$ for the design flow rate of $1.02 \mathrm{~kg} / \mathrm{s}(0.51 \mathrm{~kg} / \mathrm{s}$ in the model) and $0.11 \mathrm{MPa}$ for a $20 \%$ higher flowrate of $1.224 \mathrm{~kg} / \mathrm{s}(0.612 \mathrm{~kg} / \mathrm{s}$ in the model $)$ in Case 2.6. Cases 2.4 through 2.9 demonstrated the sensitivity of the model to nuclear heating levels and distribution, liquid deuterium mass flowrate, and convection heat transfer at the inner wall of the beryllium baffle. The angle $\theta$ referred to under the column heading "Heat flux distribution" is the angle with respect to the horizontal, where $\theta=0$ is the point on the cold source surface nearest to the reactor, (see Fig. 11). Cases 2.10 and 2.11 checked the sensitivity of the model when the annulus width was increased to $3 \mathrm{~mm}$ for uniform and distributed nuclear heating respectively. The increased cross-sectional flow area reduced the pressure drop to $0.04 \mathrm{MPa}$.

For all of the simulations studied, the liquid deuterium remained subcooled over the complete flow path through the annulus. In calculating wall superheat $\left(T_{\text {wall }}-T_{\text {sat }}\right)$, the saturation temperature, $T_{\text {sar }}$ for each case was determined from the minimum calculated pressure equal to $0.4 \mathrm{MPa}$ (the design supply pressure at the inlet to the cold source) minus the total $\Delta P$. Since most of the pressure loss occurred in the transition between the $38-\mathrm{mm}-\mathrm{ID}$ inlet line and the annulus, the outlet pressure was close to (but always less than) the local pressure at the point of maximum wall superheat. Localized regions of wall superheat ranging from 1 to $3 \mathrm{~K}$ were observed in the $2-\mathrm{mm}$-wide annulus. Increasing the annulus width to $3 \mathrm{~mm}$ produced maximum wall superheat values up to $5 \mathrm{~K}$. The calculated temperature distributions for the beryllium inner shell were below the saturation temperature of liquid deuterium for all 13 test cases.

Case 2.12 represents the current baseline calculation and includes the most recent nuclear heating estimates for the aluminum containment vessel $(10.69 \mathrm{~kW}$ for the reactor-side hemisphere) and beryllium baffle $(2.74 \mathrm{~kW})$. The nuclear heating within the containment vessel was distributed as a function of distance from the reactor with a cosine function so that the peak heat load occurred at the equator, and the integrated load over the near-reactor-side hemisphere was $10.69 \mathrm{~kW}$. This distribution is conservative in the sense that it overestimates the peak heat loads at the equator, where the liquid deuterium velocities are minimum. The nuclear heating of the beryllium baffle was distributed uniformly over the shell. Figure 12 shows the computed temperature distribution for Case 2.12 . The maximum vessel temperature of $30.7 \mathrm{~K}$ and maximum superheat of $2.3 \mathrm{~K}$ occurred at approximately $8^{\circ}$ below the equator. The first liquid deuterium node next to the maximum wall temperature node has a subcooled temperature of $23.7 \mathrm{~K}$. Across the channel at the beryllium baffle, the liquid deuterium temperature near the wall is $21.8 \mathrm{~K}$ with a corresponding $22.9 \mathrm{~K}$ wall temperature for the beryllium baffle. The temperature gradient across the beryllium baffle is $\sim 0.1 \mathrm{~K}$. Smoothly varying levels of wall superheat were calculated along the aluminum vessel between latitudinal angles $23^{\circ}$ above and $40^{\circ}$ below the equatorial plane. Outside of this region, the annulus wall temperatures were below the saturation temperature. With the flow converging at the annulus exit, a jet is formed as the liquid deuterium enters the interior of the cold source. 


\section{ANS COLD SOURCE}

20 AXISWMETHC MODELOF SPHEFICAL ANUULUS NONDNIFORM HEATWN COSME DISTRIBUTLW

$$
2 \text { mm gap }
$$

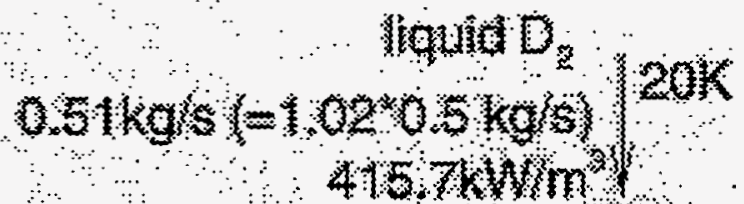

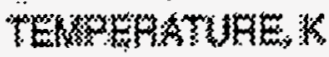

我

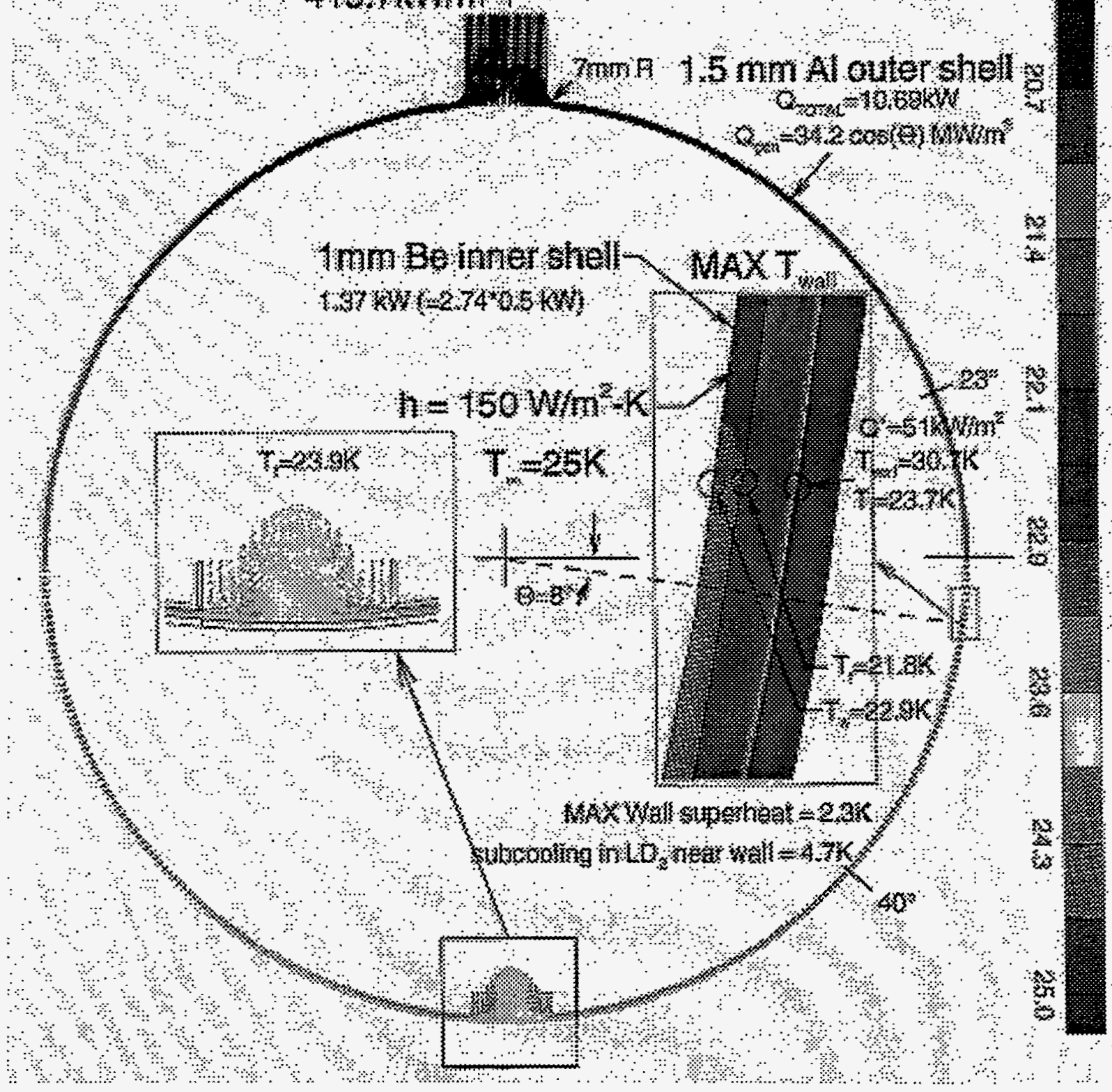

Fig. 12. Temperatures for baseline Case 2.12. 
Although the model was not able to predict vapor generation explicitly, sufficient information was available from the simulation to perform some preliminary calculations. The theoretical analysis of Frost and Dzakowic ${ }^{10}$ presents a method of calculating the minimum required wall superheat for the initiation of vapor-bubble nucleation. In their study, the wall heat flux at the onset of nucleation, $\phi_{O N B}$, is given by the relation

$$
\phi_{O N B}=\frac{k_{f}}{4 B}\left[\frac{\left(\Delta T_{S A T}\right)_{O N B}}{\operatorname{Pr}_{f}}\right] ; B \equiv\left(\frac{2 \sigma T_{S A T} v_{f g}}{h_{f g}}\right),
$$

where $k_{f}, \sigma, T_{S A T}, v_{f g}, h_{f g}$, and $\operatorname{Pr}_{f}$ are the liquid thermal conductivity, surface tension, saturation temperature, latent specific volume, latent heat of vaporization, and liquid Prandtl number respectively. Solving Eq. (20) for the wall superheat, one obtains

$$
\left(\Delta T_{S A T}\right)_{O N B}=\operatorname{Pr}_{\mathrm{f}}\left(\frac{4 B \phi_{O N B}}{k_{f}}\right)^{\frac{1}{2}} .
$$

For the heat fluxes, annulus geometry, and fluid properties in the baseline case (Case 2.12), bubble nucleation is predicted by Eq. (21) to occur for wall-superheat temperatures greater than $\sim 0.4 \mathrm{~K}$. Since the calculated maximum wall superheat is $2.3 \mathrm{~K}$, incipient nucleate boiling is probable.

As heat conducts from the wall into the bubble, vapor continues to be generated, and the bubble continues to grow until it breaks away from the wall. The size of the bubble at departure, $Y_{B}$, can be estimated by the theoretical model of Levy ${ }^{11}$ based on a force balance between the drag imposed on the bubble by the bulk flow and the surface tension of the liquid/vapor interface contacting the wall. The Levy model uses the relation

$$
Y_{B}=0.015\left(\frac{\sigma D_{h}}{\tau_{w}}\right)^{\frac{1}{2}} \text {, }
$$

where $\tau_{w}$ is the shear stress at the wall, approximated by

$$
\tau_{w}=f_{f o} \frac{\left(\dot{m} / A_{x}\right)^{2}}{2 \rho_{f}}
$$

The single-phase Fanning friction factor, $f_{f o}$ corresponding to a relative roughness $\epsilon / D_{h}=10^{-4}$ for smoothdrawn tubing, can be calculated from the relation by the Russian researcher Altshul ${ }^{12}$

$$
f_{f o}=0.025\left(1.46 \frac{\epsilon}{D_{h}}+\frac{100}{\operatorname{Re}}\right)^{0.25} .
$$

For a baseline velocity of $2.65 \mathrm{~m} / \mathrm{s}$ at the equator, the bubble size at departure is $\sim 0.024 \mathrm{~mm}$. 
An estimate for the corresponding subcooling at bubble departure can be calculated from the work of Kroeger and Zuber ${ }^{13}$, specifically

$$
\Delta T_{S U B}=153.0\left(\frac{\rho_{f} \phi_{O N B}}{\dot{m} c_{p f}}\right)
$$

For the base case conditions, the subcooling at bubble departure is $\sim 2.1 \mathrm{~K}$ by Eq. (25) coMPared to the mean flow subcooling level of $4.7 \mathrm{~K}$ calculated by the model, indicating that bubble collapse soon after departure is probable. This small bubble size is an encouraging result, since it indicates that incipient nucleation will not produce bubbles that extend across a significant portion of the annulus width. However, it is still a design goal to have subcooled walls along the complete flow path. One approach is to increase the liquid deuterium velocities in critical regions by selectively decreasing the flow cross-sectional area.

In Figure 13, the inner baffle has been divided into three sections with the upper and lower section providing a uniform 2-mm gap near the inlet and outlet of the annulus. The geometry of the containment vessel remains the same as the baseline case. The central section of the baffle is replaced by a nonspherical shell in the form of a "bulge" that creates a variable annulus width smoothly changing from $2 \mathrm{~mm}$ to $1 \mathrm{~mm}$ at the equator and then back to $2 \mathrm{~mm}$. The temperature distribution calculated in Case 2.13 for this configuration produced subcooled wall temperatures in the region immediately above and below the equatorial plane. Wall superheat was still observed downstream of the equator, as in Case 2.12. The results of Case 2.13 offer encouragement that, by additional modifications to the annulus geometry, a completely subcooled annulus design can be developed.

An additional set of cases was run with the 2-D model to determine the sensitivity of the maximum vessel and baffle temperatures to misalignment errors in the location of the baffle relative to the vessel. As shown in Fig. 14, the model was modified to allow for different centers of curvature for the inner baffle and the vessel outer shell. The center of curvature for the baffle is offset by $(\Delta x, \Delta y)$ relative to the fixed center of curvature for the vessel. For these cases, the nuclear heating rates of the vessel, baffle, and liquid $\mathrm{D}_{2}$ were also modified to correspond to the most recent neutronics calculations for the cold source by R. A. Lillie (see Fig. 15). ${ }^{14}$ The maximum nuclear heating rate occurs at the point on the vessel equator nearest the reactor. In Table 3, Cases 3.1 to 3.5 assume a beryllium baffle, and Cases 3.6 to 3.10 assume an aluminum baffle. The results of the sensitivity study show that, even though the baffle temperatures are relatively insensitive to misalignment errors, the vessel maximum temperature can be significantly increased if the inner baffle has a horizontal offset of $1 \mathrm{~mm}$ that widens the annular gap in the regions of peak nuclear heating near the vessel equator (Cases 3.2 and 3.7). The pressure drop through the annulus is most sensitive to vertical misalignments with a baffle geometry that is offset $1 \mathrm{~mm}$ below where it should be (Cases 3.5 and 3.10), resulting in a factor of 3 increase in pressure drop over the perfectly aligned cases (Cases 3.1 and 3.6).

\subsection{FUTURE THERMAL-HYDRAULIC STUDIES}

Because of the presence of the reentrant cavity and nonuniform nuclear heating of the liquid $\mathrm{D}_{2}$, vessel, and internal baffles, the analysis of the flow and heat transfer within the cold source interior must ultimately be 3-D. Therefore, 3-D models of the complete cryostat were planned for future thermalhydraulic studies. Such models would include conjugate heat transfer with nuclear heating within the cryostat vessel, internal baffling, and the reentrant cavity walls. Predicting the effects of turbulent mixing on the mean flow field would require the most sophisticated turbulence models available, specifically an Algebraic Stress Model or a Reynolds Flux Model. The goal of the modeling would be to predict 


\section{ANS COLD SOURCE}

2D AXISYMVETRIC WODEL OE SPHEFICAL ANNULUS

MONONOWWHEATIG

vatiale as widt:

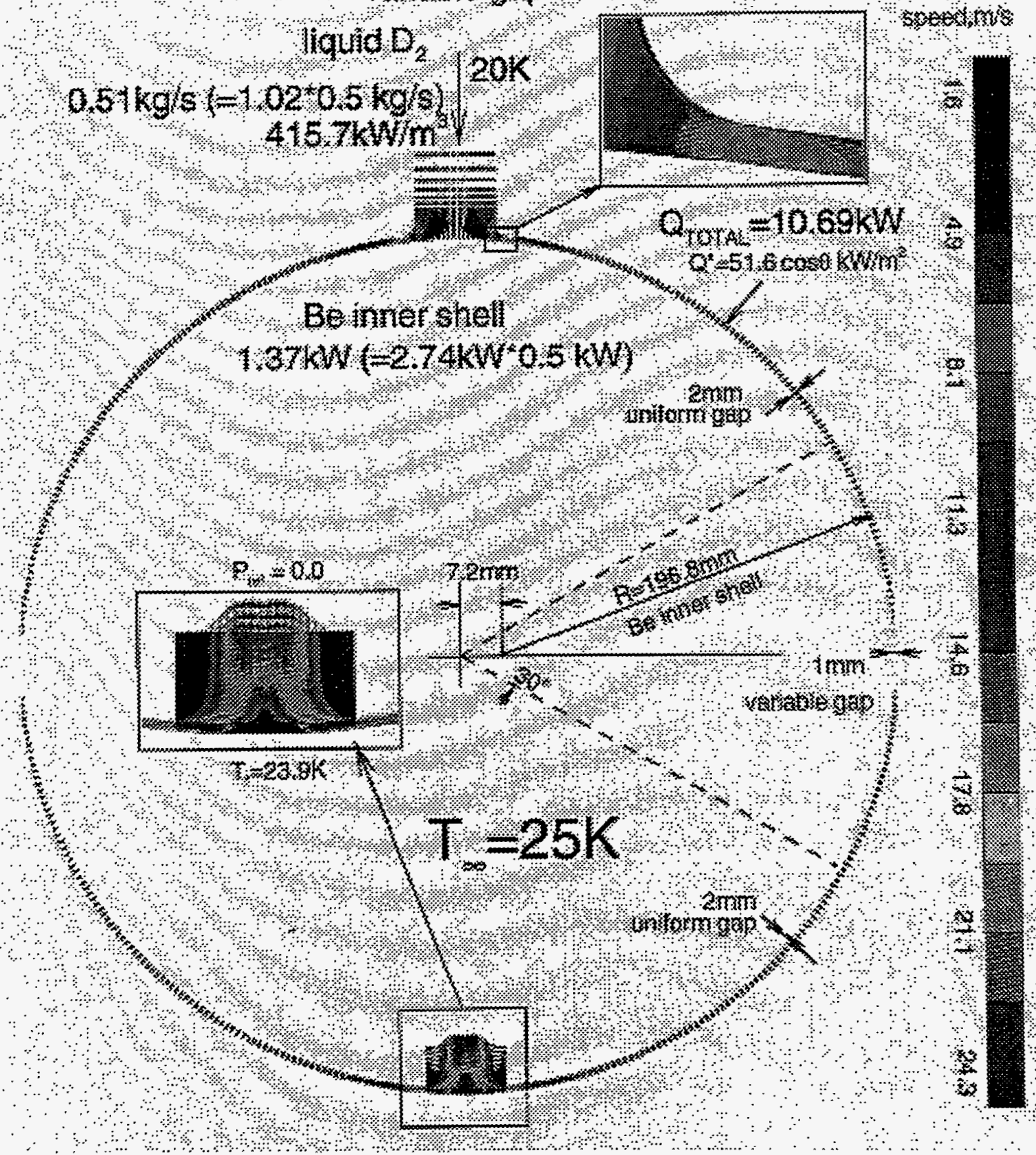

Fig. 13. Case 2.13-variable gap width. 


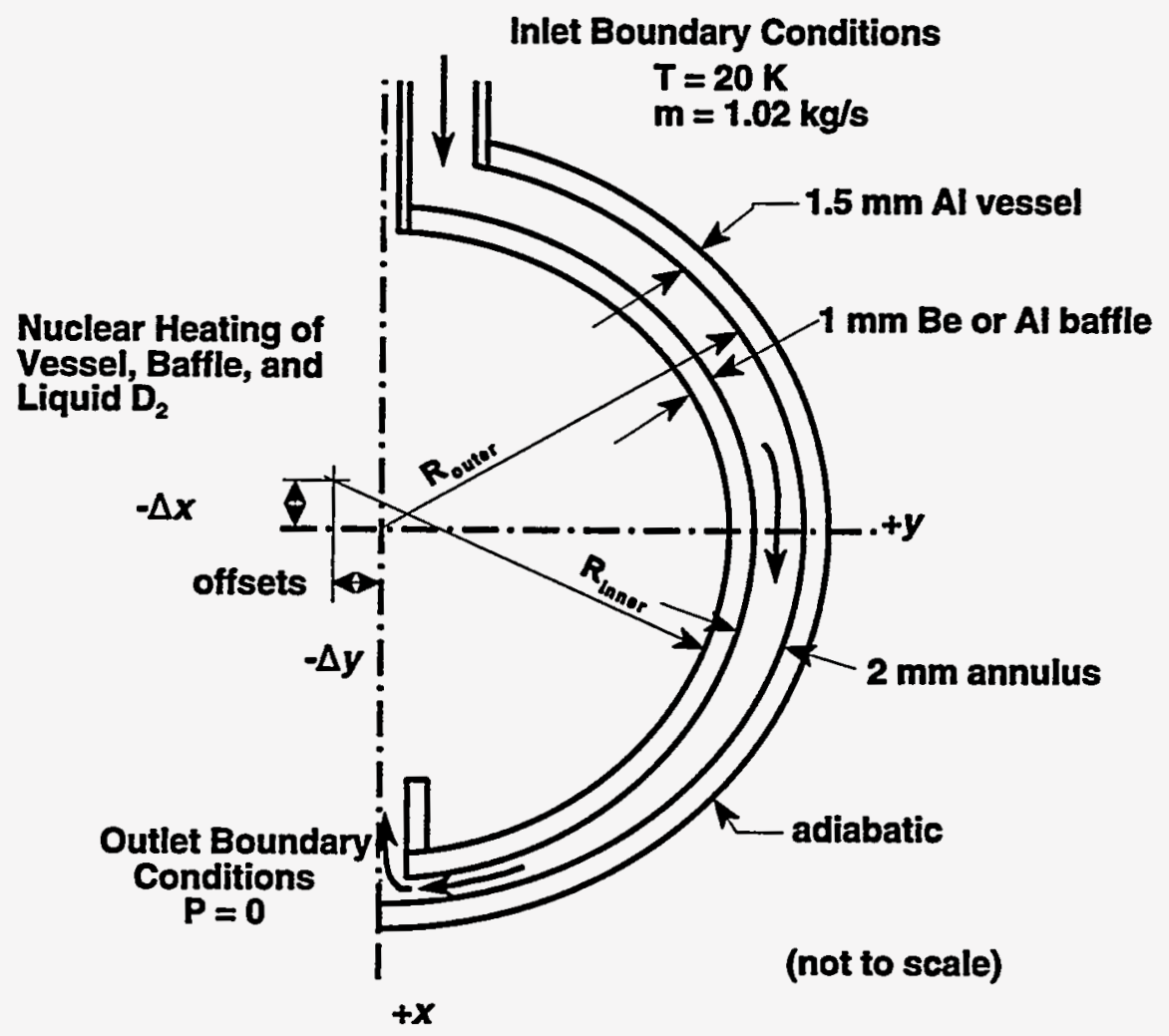

Fig. 14. Baffle misalignment model. 


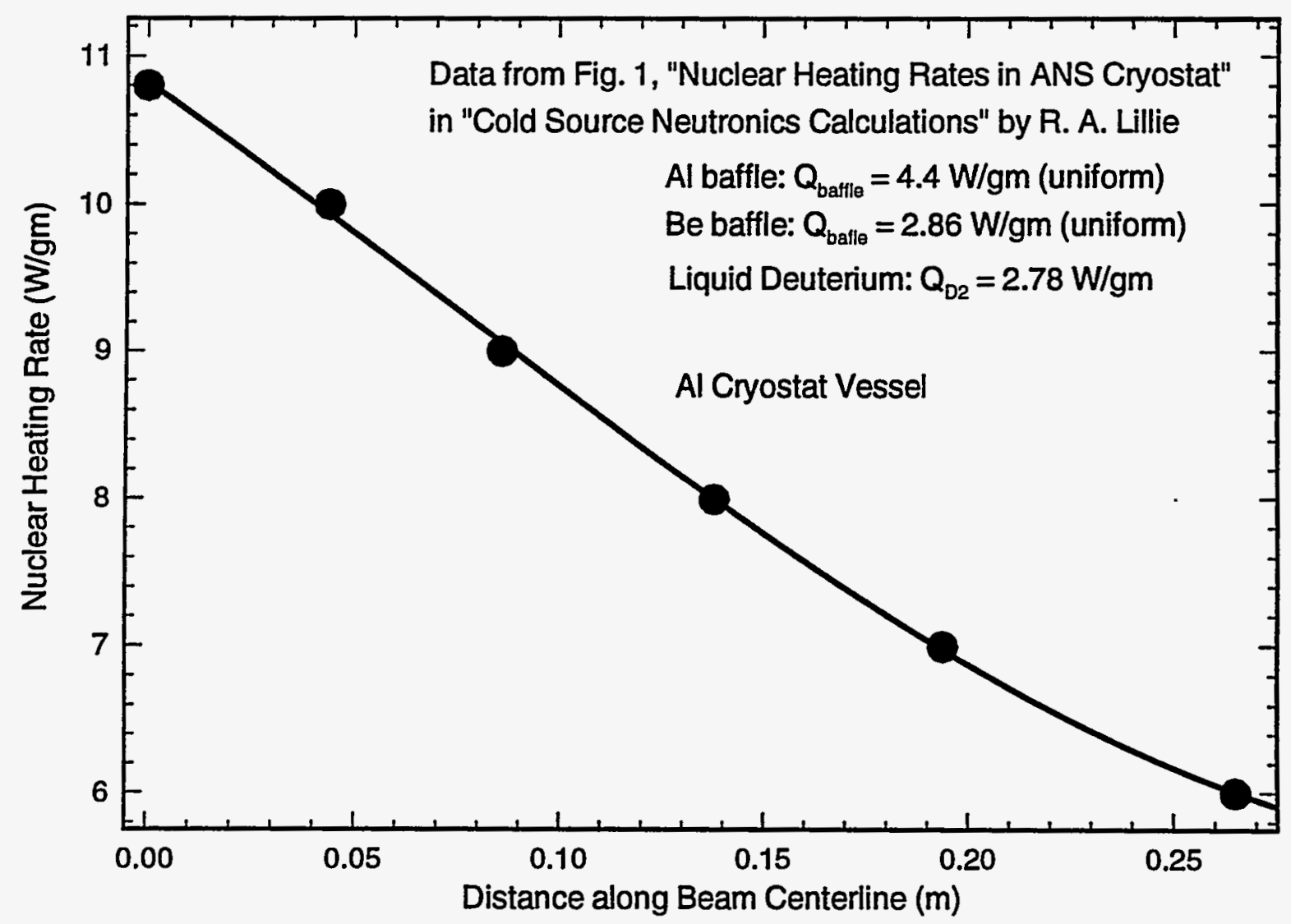

Fig. 15. Nuclear heating rates for cold source. 
Table 3. Baffle/vessel misalignment case results

\begin{tabular}{|c|c|c|c|c|c|c|c|c|c|c|}
\hline \multirow{3}{*}{$\begin{array}{c}\text { Case } \\
\text { No. }\end{array}$} & \multicolumn{5}{|c|}{ Nuclear heating rates for reactor-side hemisphere } & \multicolumn{2}{|c|}{ Vessel/baffle misalignment } & \multirow{3}{*}{$\begin{array}{l}\text { Max. vessel } \\
\text { temp. } \\
\text { (K) }\end{array}$} & \multirow{3}{*}{$\begin{array}{l}\text { Max. baffle } \\
\text { temp. } \\
\text { (K) }\end{array}$} & \multirow{3}{*}{$\begin{array}{l}\text { Total pressure } \\
\text { drop in annulus } \\
\text { (MPa) }\end{array}$} \\
\hline & \multirow{2}{*}{$\begin{array}{l}\text { Vessel }^{a} \\
(\mathrm{~kW})\end{array}$} & \multicolumn{2}{|c|}{ Baffle } & \multicolumn{2}{|c|}{ Liquid $\mathrm{D}_{2}$} & \multirow{2}{*}{$\begin{array}{l}\text { Horizontal } \\
\text { offset } \\
\text { (mm) }\end{array}$} & \multirow{2}{*}{$\begin{array}{l}\text { Vertical } \\
\text { offset } \\
(\mathrm{mm})\end{array}$} & & & \\
\hline & & $(W / g)$ & $(\mathrm{kW})$ & $(W / g)$ & $(\mathrm{kW})$ & & & & & \\
\hline 3.1 & 10.839 & 2.86 & 2.045 & 4.40 & 0.481 & 0 & 0 & 32.4 & 24.8 & 0.0583 \\
\hline 3.2 & 10.839 & 2.86 & 2.027 & 4.40 & 0.636 & -1 & 0 & 35.7 & 24.6 & 0.0642 \\
\hline 3.3 & 10.839 & 2.86 & 2.063 & 4.40 & 0.325 & +1 & 0 & 29.0 & 25.2 & 0.0594 \\
\hline 3.4 & 10.839 & 2.86 & 2.045 & 4.40 & 0.481 & 0 & -1 & 33.7 & 24.9 & 0.0735 \\
\hline 3.5 & 10.839 & 2.86 & 2.045 & 4.40 & 0.481 & 0 & +1 & 32.8 & 25.6 & 0.189 \\
\hline 3.6 & 10.839 & 4.40 & 3.147 & 2.78 & 0.304 & 0 & 0 & 32.5 & 25.3 & 0.0583 \\
\hline 3.7 & 10.839 & 4.40 & 3.119 & 2.78 & 0.401 & -1 & 0 & 35.8 & 25.4 & 0.0642 \\
\hline 3.8 & 10.839 & 4.40 & 3.174 & 2.78 & 0.205 & +1 & 0 & 29.3 & 25.7 & 0.0594 \\
\hline 3.9 & 10.839 & 4.40 & 3.147 & 2.78 & 0.304 & 0 & -1 & 33.9 & 25.8 & 0.0735 \\
\hline 3.10 & 10.839 & 4.40 & 3.147 & 2.78 & 0.304 & 0 & +1 & 32.4 & 25.2 & 0.189 \\
\hline
\end{tabular}

The vessel nuclear heating in the reactor-side hemisphere is distributed as a function of distance along the beam tube. The maximum level of $10.806 \mathrm{~W} / \mathrm{g}$ occurs on the vessel equator at the point nearest the reactor, and the minimum $(6.788 \mathrm{~W} / \mathrm{g})$ occurs at the vessel spherical shell center of curvature. 
accurately flow fields and temperature distributions so that the ability of the cold source design to maintain single-phase flow for nominal steady-state operating conditions could be assessed. Operational transients such as cooldown and heatup operations would also need to be analyzed. During these transients, both vapor and liquid phases would normally occur, thus requiring the model to simulate vapor generation and condensation in a multiphase flow environment with internal nuclear heating.

Thermal-hydraulic analysis of the complete primary and secondary cooling systems for both steady-state and transient operation is also necessary. Such thermal-systems models are typically 1-D and have the capability of simulating single-phase and/or multiphase flow with internal heat generation and external heat transfer through piping, fittings, valves, pumps, heat exchangers, accumulators, etc. An example of such a computational tool employed in reactor thermal-hydraulic studies of light- and heavy-water systems in power and research nuclear reactors is the RELAP5 code. ${ }^{15}$ A similar code would have to be identified for multiphase transient cryogenic thermal analysis. If neither a suitable commercial nor public-domain code could be found, then an in-house computational tool would need to be developed. In addition to normal operational transients, the code should also be capable of simulating abnormal transients such as loss-of-coolant and equipment-failure accidents for both systems design and safety studies. 


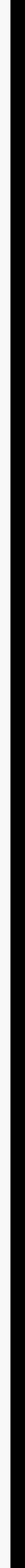




\section{CONCLUSIONS AND RECOMMENDATIONS}

The preliminary thermal-hydraulic computational studies for the ANS cold source vessel design have been aimed at demonstrating the feasibility of achieving the necessary heat transfer at the vessel walls without producing a significant net vapor generation. Any practical engineering design is the result of optimization and arriving at the best-considered compromise. The scale of this problem, and the need for accurate results, present a considerable challenge. However, the modeling to date is relatively basic, and accordingly some fundamental assumptions have been made. As the model complexity increases, 3-D effects, caused by nonuniform heating, and the presence of an internal cavity would have to be considered. Also, the effects of temperature gradients within the inner chamber would need to be investigated. Manufacturing difficulties and the ability to maintain the annulus geometry after temperature excursions and high levels of radiation might force the design of a more complex baffle configuration. This design effort would have to be the subject of future work extending the results of the analyses described herein with integrated 3-D multiphase numerical models of the cold source interior. Complete systems analyses of the primary and secondary cryogenic loops were also planned which would typically be 1-D, multiphase, transient models designed to simulate both nominal operational transients as well as abnormal fast-transient accident scenarios. Such a systems analysis approach is important for both the design phase and the safety analysis phase of the cold source development program.

Physical testing was planned to supplement the computer modeling. Initially surrogate fluids would have been used to examine the merits of alternative configurations. All designs, however, must seriously limit the mass of material used as this directly affects the overall heat load. The final design would have been validated using full-scale experimental tests to which realistic heat loads would be applied with an authentic flow of liquid deuterium. Heat would be applied to the vessel walls by induction coils providing $15 \mathrm{~kW}$ of heat to represent nuclear heat generation in the vessel. After the liquid deuterium exits the annulus, a further $15 \mathrm{~kW}$ would be added by an external heater before the flow reenters the interior of the cold source sphere. During this test, the outer surface of the vessel would be scanned to identify any high-temperature regions, which would indicate poor heat transfer. A further test would use a full-scale loop, built to the correct geometry, to demonstrate the ability of the system design to fill and subcool the loop in its final configuration. A refrigerator capacity of only about $2 \mathrm{~kW}$ would have been sufficient to simulate realistic cooldown conditions. 
$--$ - - 


\section{REFERENCES}

1. C. D. West, "The U. S. Advanced Neutron Source," Advanced Neutron Sources 1988, Proc. 10th Meeting of the Int. Collaboration on Advanced Neutron Sources (ICANS X), 97, 643-654 (1988).

2. K. W. Childs, HEATING7.2 User's Manual, ORNL/TM-12262, Martin Marietta Energy Systems, Oak Ridge National Laboratory, February 1993.

3. Y. S. Touloukian, R. W. Powell, C. Y. Ho, and P. C. Klemens, Thermophysical Properties of Matter, Vol. 1, Thermal Conductivity of Metallic Elements and Alloys, IFI/Plenum, New York, 1970.

4. W. H. McAdams, Heat Transmission, McGraw-Hill, New York, 1954, p. 219.

5. CFDS-FLOW3D Release 3.2 User's Manual, AEA Industrial Technology, Harwell, Oxfordshire, UK, 1994.

6. J. P. Van Doormaal and G. D. Raithby, "Enhancements of the SIMPLE Method for predicting Incompressible Fluid Flows," Numer. Heat Transfer 7, 147-163 (1974).

7. B. E. Launder and D. B. Spaulding, "The Numerical Computation of Turbulent Flows," Comput. Methods Appl. Mech. Eng. 3, 269-289 (1974).

8. D. S. Clarke and N. S. Wilkes, "The Calculation of Turbulent Flow in Complex Geometries Using a Differential Flux Model," AEA-InTec-0216, Harwell, Oxfordshire, UK, 1991.

9. C. R. Bass, "Thermal-Hydraulic Characterization of a Cryogenic Neutron Cold-Source," Ph.D. Dissertation, University of Virginia, 1994.

10. W. Frost and G. S. Dzakowic, "An Extension of the Method of Predicting Incipient Boiling on Commercially Finished Surfaces," presented at the ASME-AIChE Heat Transfer Conference, Seattle, Wash., 67-HT-61, August 1967.

11. S. Levy, "Forced Convection Subcooled Boiling. Prediction of Vapour Volumetric Fraction," Int. J. Heat Mass Transfer 10, 951-965 (1967).

12. I. E. Idel'Chik, Handbook of Hydraulic Resistance, Coefficients of Local Resistance and Friction, 1960, translated from the Russian by the Israel Program for Scientific Translations, AEC-TR-6630, 1966.

13. P. G. Kroeger and N. Zuber, "An Analysis of the Effects of Various Parameters on the Average Void Fractions in Subcooled Boiling," Int. J. Heat Mass Transfer 11, 211-233 (1968). 
14. R. A. Lillie, "Cold Source Neutronics Calculations," ANS Monthly Progress Report, 1994.

15. K. E. Carlson, R. A. Riemke, S. Z. Rouhani, R. W. Shumway, and W. L. Weaver, RELAP5/MOD3 Code Manual Volume II: User's Guide and Input Requirements, EGG2596, EG\&G Idaho, Idaho National Engineering Laboratory, June 1990. 


\section{Internal Distribution}

1-5. J. H. Campbell

6. J. E. Cleaves

7. R. L. Johnson

8. A. T. Lucas

9. D. L. Selby

10. C. D. West

11. P. T. Williams
12. ORNL Patent Office

13-14. Central Research Library

Document Reference Sect.

15. Y-12 Technical Library

16-17. Laboratory Records Dept.

18. Laboratory Records, RC

\section{External Distribution}

19. U.S. Department of Energy, ANS Project Office, Oak Ridge Operations Office, FEDC, MS-8218, P.O. Box 2009, Oak Ridge, TN 37831-8218.

20-21. Office of Scientific and Technical Information, P.O. Box 62, Oak Ridge, Tennessee 37831. 
, 